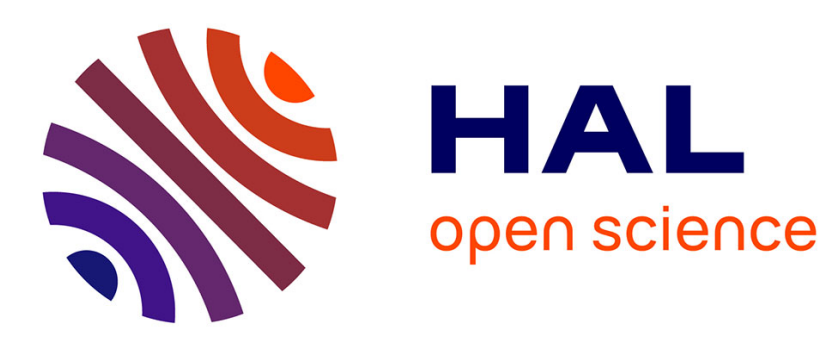

\title{
A three-source SVAT modeling of evaporation: Application to the seasonal dynamics of a grassed vineyard
}

Carlo Montes, Jean-Paul Lhomme, Jérôme Demarty, Laurent Prevot, Frédéric Jacob

\section{To cite this version:}

Carlo Montes, Jean-Paul Lhomme, Jérôme Demarty, Laurent Prevot, Frédéric Jacob. A three-source SVAT modeling of evaporation: Application to the seasonal dynamics of a grassed vineyard. Agricultural and Forest Meteorology, 2014, 191, pp.64-80. 10.1016/j.agrformet.2014.02.004 . hal-01863507

\section{HAL Id: hal-01863507 https://hal.science/hal-01863507}

Submitted on 5 Nov 2021

HAL is a multi-disciplinary open access archive for the deposit and dissemination of scientific research documents, whether they are published or not. The documents may come from teaching and research institutions in France or abroad, or from public or private research centers.
L'archive ouverte pluridisciplinaire HAL, est destinée au dépôt et à la diffusion de documents scientifiques de niveau recherche, publiés ou non, émanant des établissements d'enseignement et de recherche français ou étrangers, des laboratoires publics ou privés. 
11 a Institut de Recherche pour le Développement, UMR LISAH, 34060 Montpellier, France

12 ' Institut de Recherche pour le Développement, UMR HSM, 34095 Montpellier, France

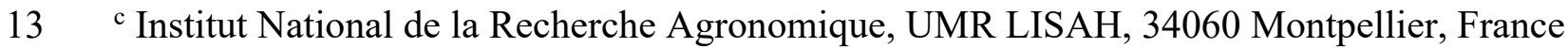

\footnotetext{
* Corresponding author address:
}

Carlo Montes, UMR LISAH, 2 place Pierre Viala, 34060 Montpellier, France E-mail address: ccmontesv@gmail.com 


\section{Abstract.}

18 A parsimonious and versatile Soil-Vegetation-Atmosphere Transfer (SVAT) model is 19 proposed for three component vineyards, which includes vine foliage, grassed soil and bare 20 soil. A three-source energy balance approach describes the energy and mass transfer between

21 the soil-plant continuum and the lower atmosphere with an hourly time step. It is coupled with

22 a soil water balance module running with a daily time step. The model makes use of standard

23 meteorological data together with parameters describing foliage development, grass and soil

24 characteristics. The model is calibrated by means of the Multi-objective Calibration Iterative

25 Process (MCIP) algorithm and next validated for evaporation and soil moisture over a dataset

26 collected in a Southern France grassed vineyard. The validation exercise is twofold. It focused

27 first on the daily course of evaporation derived from the surface energy balance module only,

28 forced with weather variables, net radiation and soil moisture. The comparison against Eddy

29 Covariance measurements shows a good agreement $\left(R^{2}=0.96\right.$ and RMSE $\left.=14.0 \mathrm{~W} \mathrm{~m}^{-2}\right)$.

30 Next, a simulation coupling the surface energy balance module with the soil water balance

31 module is validated over Eddy Covariance and soil moisture measurements. Simulations

32 throughout two contrasting growing seasons provide good estimates of daily evaporation $\left(R^{2}\right.$

$33=0.90$ and $\left.\operatorname{RMSE}=0.43 \mathrm{~mm} \mathrm{~d}^{-1}\right)$ and soil water content $\left(R^{2}=0.98\right.$ and $\left.\operatorname{RMSE}=6.95 \mathrm{~mm}\right)$.

34 Model inaccuracies arise mainly under conditions of strong surface runoff. Results also 35 suggest that the parameterizations relating the surface-atmosphere module with the soil 36 module (i.e. stomatal resistance) should be carefully examined under water stress conditions.

37 Finally, the model versatility is addressed through a set of static simulations. It appears that 38 the modeling approach allows assessing the seasonal water balance of vineyards differing by

39 their structure (varying grass fraction or distance between rows) and of similar cropping 40 systems.

42 Key words: latent heat flux; multi-source; sparse vegetation; soil water balance; seasonal 43 course 


\section{List of symbols}

$50 A_{i}$ : available energy for each component $v s$ and $b s\left(\mathrm{~W} \mathrm{~m}^{-2}\right)$

$51 A_{f}$. available energy for the main foliage $\left(\mathrm{W} \mathrm{m}^{-2}\right)$

$52 c$ : radiation extinction coefficient by canopy

$53 c_{p}$ : specific heat of air at constant pressure $\left(\mathrm{J} \mathrm{kg}^{-1} \mathrm{~K}^{-1}\right)$

$54 C R_{3}$ : capillary rise into reservoir (3) (mm)

$55 d$ : displacement height (m)

$56 D_{1}$ : drainage from reservoir (1) to $(3)(\mathrm{mm})$

$57 D_{2}$ : drainage from reservoir (2) to $(3)(\mathrm{mm})$

$58 D_{3}$ : deep percolation from reservoir (3) $(\mathrm{mm})$

$59 D_{a}$ : vapor pressure deficit at reference height $(\mathrm{Pa})$

$60 D_{m}$ : vapor pressure deficit at mean canopy source height $(\mathrm{Pa})$

$61 e_{a}$ : vapor pressure at reference height $(\mathrm{Pa})$

$62 e^{*}\left(T_{i}\right)$ : saturated vapor pressure at temperature $T_{i}(i=f, v s, b s)(\mathrm{Pa})$

$63 F_{b s}$ : fraction of bare soil $\left(=1-F_{v s}\right)$

$64 F_{v s}$ : fraction of vegetated soil

$65 \quad F_{1}=F_{b s}$

$66 \quad F_{2}=F_{v s}$

$67 G_{v s}$ : soil heat flux of vegetated soil $\left(\mathrm{W} \mathrm{m}^{-2}\right)$

$68 G_{b s}$ : soil heat flux of bare soil $\left(\mathrm{W} \mathrm{m}^{-2}\right)$

$69 I_{v s}$ : infiltration term for vegetated soil $(\mathrm{mm})$

$70 I_{b s}$ : infiltration term for bare soil (mm)

$71 K\left(z_{h}\right)$ : turbulent diffusivity at canopy height $\left(\mathrm{m}^{2} \mathrm{~s}^{-1}\right)$

72 L: Monin-Obukhov length (m)

$73 L A I_{f}$. leaf area index of main foliage $\left(\mathrm{m}^{2} \mathrm{~m}^{-2}\right)$

$74 C L A I_{v s}$ : clumped leaf area index of vegetated soil $\left(\mathrm{m}^{2} \mathrm{~m}^{-2}\right)$

$75 n$ : parameter with value of 1 for amphistomatous and 2 for hypostomatous foliage

$76 r_{a}$ : aerodynamic resistance between the mean source height $\left(z_{m}\right)$ and the reference height $\left(z_{r}, \mathrm{~s}\right.$ $\left.77 \mathrm{~m}^{-1}\right)$

$78 r_{a, i}$ : aerodynamic resistance between the evaporative source $(i=v s, b s)$ and mean source

79 height $\left(z_{m}, \mathrm{~s} \mathrm{~m}^{-1}\right)$

$80 r_{a, f, h}$ : bulk boundary-layer resistance of the foliage for sensible heat $\left(\mathrm{s} \mathrm{m}^{-1}\right)$ 
$81 r_{s, i}:$ surface resistance (stomatal or soil surface) for each source $(i=f, v s, b s)\left(\mathrm{s} \mathrm{m}^{-1}\right)$

$82 R_{n}$ : net radiation of the whole canopy $\left(\mathrm{W} \mathrm{m}^{-2}\right)$

$83 u_{a}$ : wind speed at reference height $\left(\mathrm{m} \mathrm{s}^{-1}\right)$

$84 z_{h}$ : height of the main foliage (m)

$85 z_{m}$ : mean source height $(\mathrm{m})$

$86 z_{r}$ : reference height $(\mathrm{m})$

$87 z_{0}$ : roughness length for momentum of main foliage $(\mathrm{m})$

$88 z_{0}^{i}$ : roughness length for momentum of vegetated $(i=v s)$ or bare soil $(i=b s)(\mathrm{m})$

$89 z_{1}$ : depth of soil reservoir (1) (m)

$90 \quad z_{2}$ : depth of soil reservoir $(2)(\mathrm{m})$

$91 z_{R}$ : vines rooting depth $(\mathrm{m})$

$92 z_{G}$ : water table depth (m)

$93 \gamma$ : psychrometric constant $\left(\mathrm{Pa} \mathrm{K}^{-1}\right)$

$94 \lambda$ : latent heat of vaporization $\left(\mathrm{J} \mathrm{kg}^{-1}\right)$

$95 \Delta$ : slope of the saturated vapor pressure curve at air temperature $\left(\mathrm{Pa} \mathrm{K}^{-1}\right)$

$96 \rho$ : air density $\left(\mathrm{kg} \mathrm{m}^{-3}\right)$

$97 \phi_{s}$ : solar zenith angle (radians)

98

99 
Progress in theoretical and applied research aiming at accurately assessing crop water consumption in both rain-fed and irrigated conditions is an essential issue for agricultural water management. Since evaporation measurements are scarce, operational formulations to estimate water consumption at field scale are necessary (Trambouze et al., 1998; Spano et al., 2009). For viticulture regions in Mediterranean and semi-arid environments, actual evaporation represents a major component of surface water balance, reaching up to $70 \%$ of the yearly precipitation (Moussa et al., 2007). Knowledge of actual evaporation is also of interest in viticulture, in order to assess and handle the influence of soil water deficit on grapevine yields and berry composition (Vaudour, 2003; Pellegrino et al., 2005). Nevertheless, the physical representation of the soil-plant-atmosphere system in grapevines is a complex issue, because the sparse structure of vineyards imposes to consider both the foliage and the understory, which requires multi-source modeling.

The most frequently used multi-source evaporation model is the one first developed by

115 Shuttleworth and Wallace (1985) (S-W model) and extended by Choudhury and Monteith 116 (1988) and Shuttleworth and Gurney (1990). This model corresponds to an extension of the 117 big-leaf model of Penman-Monteith (Monteith, 1965) into two interacting evaporative layers:

118 the main foliage and the underlying substrate. Subsequently, the S-W model was upgraded by

119 Brenner and Incoll (1997) ("clumped" model) to account for three sources of evaporation 120 after dividing the understory into a bare soil fraction and a soil fraction below the main 121 foliage, and also by Verhoef and Allen (2000) to account for four sources of evaporation. The 122 two- and three-source formalisms were revisited by Lhomme et al. (2012) to propose more 123 concise and accurate formulations and to account for foliage morphological characteristics 124 (amphistomatous versus hypostomatous leaves). All these models are based on the diffusion 125 theory ( $K$-theory) for energy and mass transfer within the lower atmosphere. More complex 126 models based on higher order Lagrangian and Eulerian dispersion processes can be found in 127 the literature: they allow a better representation of vegetation-atmosphere turbulent transfers 128 (Raupach, 1989; Yi, 2008), but their complexity and data requirement make them difficult to 129 use in a practical modeling framework. It has been shown, further, that the diffusion theory is 130 appropriate to represent the microclimate at canopy scale in comparison with Lagrangian 131 representations (van den Hurk and McNaughton, 1995; Wu et al., 2001).

132 One of the first models to estimate vineyard evaporation is the one proposed by Riou 133 et al. (1989, 1994). It is not a multi-source model: vineyard evaporation under unstressed 
134 conditions is expressed as a simple function of potential evaporation and solar radiation intercepted by the canopy. This model was extended later by Trambouze and Voltz (2001),

136 who derived a bilinear relationship relating the ratio between vineyard actual and maximum

137 transpiration to the average soil water storage. Subsequently, several authors have applied the

138 multi-source resistance-based formulations to assess vineyard evaporation. First, we have to

139 mention the work by Rana and Katerji (2008), where a simple single-source model (Penman-

140 Monteith) was applied to vineyards trained on overhead system. In an earlier work by Sene

141 (1994), the more complex S-W model was applied with the purpose of interpreting energy

142 balance measurements over a sparse vineyard in southern Spain. More recently, an

143 appropriate representation of total latent heat flux from a drip-irrigated vineyard in central

144 Chile was obtained by Ortega-Farias et al. (2007) by applying the same S-W model. In

145 addition, Poblete-Echeverria and Ortega-Farias (2009) adapted the so-called "clumped"

146 model to drip irrigation over the same region of Chile by dividing the substrate (bare soil) into

147 a dry and a wet (irrigated) portion. Zhang et al. (2008) compared these two models (S-W and

148 clumped) against Bowen ratio estimates in a semi-arid vineyard of China: they concluded that

149 the clumped model was more suitable to estimate total vineyard evaporation than the S-W

150 model. On the same basis, Zhang et al. (2009) elaborated a multi-source S-W type model to

151 simulate the evaporation from a vineyard under partial root-zone irrigation, taking into

152 consideration different patches of soil.

153 All these vineyard evaporation models, however, do not take into account the common

154 practice of maintaining a permanent or semi-permanent grass cover. This consists in a seeded

155 or natural grass cover in between vine rows, maintaining bare soil on the rows. This practice

156 is increasingly used because it has several positive impacts, such as the reduction in rainfall

157 erosive potential and surface runoff, the reduction in nutrient lixiviation, the decrease in vine

158 vigor and grape production (which improves grapes quality) and the improvements in soil

159 structure and trafficability after rainfall events (Pradel and Pieri, 2000; Morlat and Jacquet,

160 2003; Celette et al., 2005; Celette et al., 2008; Gaudin et al., 2010). As compared with the

161 traditional bare soil grapevine cultivation, the grass cover affects energy and water balance

162 since surface albedo, net radiation partitioning, water consumption and infiltration are

163 modified (Rodriguez-Iturbe, 2000; Zhang and Schilling, 2006; Centinari et al., 2012). For

164 instance, in a recent work by Holland et al. (2013) on grassed vineyard, significant differences

165 were found between grassed and bare soil energy partitioning. Therefore, this grass cover

166 component should be considered into a modelling formulation.

167 In addition, most of the vineyard evaporation models mentioned above only consider 
168 above-ground processes (i.e. vegetation and soil surface), which interact with soil water through the parameterization of a stomatal or substrate resistance to evaporation, in the best case. Thus, they do not allow the temporal dynamics of vineyard evaporation to be adequately simulated throughout the season. However, models have been developed to simulate soil water balance of vineyards. Sene (1996) was the first to combine a simple soil moisture model with a two-component (S-W) representation of vineyard evaporation in order to estimate the long-term water balance of a sparse vine crop growing under semi-arid conditions. Lebon et al. (2003) also performed simulations of the seasonal dynamics of soil water balance in vineyards by using a single reservoir soil model along with the Riou et al. $(1989,1994)$ approach for grapevine transpiration coupled with a stress function involving soil water availability (Trambouze and Voltz, 2001). Celette et al. (2010) extended the model of Lebon et al. (2003) to simulate the water balance of an intercropped vineyard considering an additional and separate soil compartment under the cover crop. Galleguillos et al. (2011) also used the model of Riou et al. (1989, 1994), but coupled with the HYDRUS-1D simulation model of soil water transfers. Although realistic results have been obtained with this type of soil water balance model, the evaporation process remains poorly represented and a more realistic approach based upon micrometeorological resistance-type models coupled with soil water models appears to be necessary.

With regards to the elements discussed above, the main objective of the present work is to develop a Soil-Vegetation-Atmosphere Transfer (SVAT) model which simulates the vineyard evaporation dynamics at seasonal scale and accounts for the grass cover as a viticultural practice. It combines a comprehensive micrometeorological three-source model of evaporation with a three reservoir soil water balance model. The formulation is versatile enough to allow the assessment of evaporation rate from different mixed cropping systems, in so far as species-specific biophysical parameters and physical soil properties descriptors are adjusted to the prevailing conditions. The formulation is also kept as parsimonious as possible to foresee its application at the regional extent while accounting for the inter-field variability. The plan is as follows. In Section 2, the SVAT model is fully described, separating the evaporation model from the soil water balance model. Section 3 details the study area, the experimental data, the model implementation and the strategy for calibration. Section 4 shows a comparison of model simulations against ground truth data to validate the model and some simulations are presented to show the versatility of the model through its aptitude to represent different viticultural practices (proportion of grassed soil and distance between rows). Finally, model results and limitations are discussed in Section 5. 


\section{Model development}

\subsection{Representing the vine-grass-soil system}

The soil-plant-atmosphere continuum is represented as a three-source system that

208 includes the vine canopy (main foliage) and a composite substrate made of a grass cover and 209 bare soil. This rain fed Cabernet Sauvignon vineyard is conducted in rows. Vine leaf area 210 index $\left(L A I_{f}\right)$ varies throughout the growing season from 0 to a maximum value and next falls 211 back to 0 during senescence. The grass cover is present only on one inter-row out of two. It is 212 characterized by the concept of clumped $L A I\left(C L A I_{v s}\right)$, defined as grass leaf area index per 213 unit area of grass cover: $C L A I_{v s}=L A I_{v s} / F_{v s}, F_{v s}$ being the proportion of vegetated soil. Grass 214 exhibits a seasonal dynamics: its growth is initiated by autumn precipitations and it dries off 215 in early summer as a result of large water stress. The bare soil fraction $\left(F_{b s}\right)$ covers the rest of 216 the inter-row and the soil below the vines. The vine-grass-soil system corresponds to a three217 source system between autumn and early summer and to a two-source system in summer, 218 when the substrate is made of bare soil and dry grass only $\left(F_{b s}=1\right)$.

219 The three components should be considered separately because they have different 220 physical and geometrical features which affect energy and mass transfers. Nevertheless, the 221 vine patches are not large enough to adopt a patch representation of the whole system and 222 consequently a layer representation is preferred (Boulet et al., 1999; Lhomme and Chehbouni, 223 1999; Anderson et al., 2005). Given the composite nature of the substrate, the modeling 224 combines a layer approach for the vine-substrate system with a patch approach for the substrate (grass cover + bare soil), as represented in Fig. 1 and explained in Lhomme et al.

226 (2012, section 3.1). Indeed, while substrate and vine are interrelated in the vertical transfer of 227 heat and water vapor with a sole aerodynamic resistance above the whole canopy, grass cover 228 and substrate are assumed to act separately vis-a-vis the canopy source height.

Soil moisture dynamics is represented by a bucket type model made of three reservoirs 230 in relation with the three components of the evaporation model: a deep reservoir 231 corresponding to the vine rooting system $(\sim 2 \mathrm{~m})$ and two shallow reservoirs corresponding to 232 the two substrate components. The main input of the system corresponds to the infiltration of 233 water from precipitation. Drainage processes control the water transfers between reservoirs. 234 Evaporation is the main output and deep percolation acts as a secondary output. Capillary rise 235 from the saturated zone below the deep reservoir is also considered, but horizontal water 
transfers (runoff) are ignored.

The SVAT model consists of coupling the surface energy balance for plant-

238 atmosphere system and the soil water balance for the subsurface system. The evaporation

239 model runs with a short time step (one hour or less) and is forced with meteorological data

240 (air temperature and humidity, wind speed, solar radiation) and vegetation data (vine height

241 and leaf area, fraction of grass cover). The soil water balance runs on a daily time step and is

242 forced with daily precipitation. The water content of each subsurface reservoir is an input to

243 the corresponding evaporation components and conversely the evaporation components are

244 inputs for the soil water balance module.

\subsection{Evaporation model}

We detail hereafter the surface energy balance and soil water balance modules

249 forming the SVAT model and their corresponding parameterizations. For the numerous

250 formulations considered in this section, the values of the corresponding parameters are given 251 in Table 1.

\subsubsection{Formulation of evaporation}

The total flux of latent heat $\left(\lambda E_{t}\right)$ is the sum of the contributions from three sources: main foliage $\left(\lambda E_{f}\right)$, vegetated soil $\left(\lambda E_{v s}\right)$ with relative area $F_{v s}$ and bare soil $\left(\lambda E_{b s}\right)$ with relative area $F_{b s}=1-F_{v s}$. They are aggregated following a coupled (or layer) approach (Fig. 1):

$\lambda E_{t}=\lambda E_{f}+\lambda E_{v s}+\lambda E_{b s}$.

The three evaporation components reach the mean canopy source height $\left(z_{m}\right)$, assumed to be located at the apparent sink for momentum (zero plane displacement height $d+$ roughness length $z_{0}$ ), where they mix together forming the total evaporation at reference height $\left(z_{r}\right)$ as it can be measured with Bowen ratio or Eddy Covariance system. The resistances network represents the controlling effects of soil surface, stomatal behavior and surrounding air, which are considered to be "in series" for each individual source. Vegetated (vs) and bare soil (bs) air resistances extend from the surface level $\left(z_{0, i}, i=v s\right.$ or $\left.b s\right)$ to the mean canopy source height $\left(z_{m}\right)$. Evaporation components are calculated from Penman-Monteith type equations 
269 involving the corresponding available energy $\left(A_{f}, A_{v s}\right.$ or $\left.A_{b s}\right)$ and the vapor pressure deficit $D_{m}$ 270 at mean canopy source height $z_{m}$. However, following Lhomme et al. (2012), the stomatal 271 characteristics of the main foliage (amphistomatous or hypostomatous) are taken into account 272 in the evaporation formulation

$$
\lambda E_{f}=\frac{\Delta A_{f}+\rho c_{p} D_{m} / r_{a, f, h}}{\Delta+\gamma\left(n+r_{s, f} / r_{a, f, h}\right)}
$$

276 where the parameter $n$ takes the value $n=1$ for amphistomatous and $n=2$ for hypostomatous 277 leaves. Since grapevine foliage is hypostomatous, we took $n=2 . \Delta$ is the slope of the 278 saturated vapor pressure curve at air temperature, $\rho$ the air density, $c_{p}$ the specific heat of air 279 at constant pressure, $\gamma$ the psychrometric constant, $r_{a, f, h}$ the foliage bulk boundary-layer 280 resistance for sensible heat and $r_{s, f}$ the bulk surface resistance of the foliage. For the two 281 substrate components (vegetated soil and bare soil) we have

$$
\lambda E_{i}=\frac{\Delta A_{i}+\rho c_{p} D_{m} / r_{a, i}}{\Delta+\gamma\left(1+r_{s, i} / r_{a, i}\right)}, \quad \text { with } i=v s \text { or } b s
$$

$r_{a, i}$ is the aerodynamic resistance between the evaporative source $(i=v s, b s)$ and $z_{m}$, and $r_{s, i}$ is 286 the surface resistance (stomatal or soil surface) for each source $(i=v s, b s)$.

$$
\lambda E_{t}=\left(\frac{\Delta+\gamma}{\gamma}\right)\left(P_{f}+P_{v s}+P_{b s}\right) \lambda E_{p}+\frac{\Delta}{\gamma}\left(P_{f} r_{a, f, h} A_{f}+P_{v s} r_{a, v s} A_{v s}+P_{b s} r_{a, b s} A_{b s}\right) / r_{a},
$$

293 where $\lambda E_{p}$ represents the potential evaporation expressed as

$$
\lambda E_{p}=\frac{\Delta A+\rho c_{p} D_{a} / r_{a}}{\Delta+\gamma}
$$


297 where $A$ is the total available energy and $r_{a}$ is the aerodynamic resistance between the source 298 height $z_{m}$ and the reference height $z_{r}$. The $P_{i}$ coefficients of Eq. (4) are combinations of 299 surface and aerodynamic resistances, detailed in Appendix A. Each evaporation component is 300 obtained from Eqs. (2) and (3) by expressing the in-canopy vapor pressure deficit $D_{m}$ as a 301 function of the saturation deficit at reference height $D_{a}$ (Shuttleworth and Wallace, 1985):

$$
D_{m}=D_{a}+\left\lfloor\Delta A-\lambda E_{t}(\gamma+\Delta) \mid r_{a} /\left(\rho c_{p}\right)\right.
$$

\subsubsection{Partition of available energy}

Total available energy $(A)$ for turbulent fluxes is defined as the difference between the total net radiation $\left(R_{n}\right)$ and the soil heat flux $(G)$ counted positively when gained by the surface: $A=R_{n}-G$. Beer's law is used to obtain the partitioning of net radiation including the effects of solar zenith angle $\left(\phi_{s}\right)$ on net radiation extinction (Anderson et al., 1997; Kustas et

311 al., 1998). Considering the canopy as a semi-transparent layer to incident radiation, the net 312 radiation reaching the substrate level $R_{n}(0)$ is obtained by

$$
R_{n}(0)=R_{n} \exp \left(-c L A I_{f} / \sqrt{2 \cos \left(\phi_{s}\right)}\right)
$$

where $c$ is the extinction coefficient of radiation of the main foliage, which depends upon leaves angular distribution (Choudhury, 1989), and $L A I_{f}$ its leaf area index. For the main vegetation canopy, the available energy $\left(A_{f}\right)$ is computed as the difference between the total

$$
A_{f}=R_{n}-R_{n}(0)=R_{n}\left|1-\exp \left(-c L A I_{f} / \sqrt{2 \cos \left(\phi_{s}\right)}\right)\right| .
$$

Soil heat flux for vegetated and bare soil ( $G_{v s}$ and $G_{b s}$, respectively) is obtained as a

324 fraction of the net radiation reaching the substrate level (Norman et al., 1995; Boulet et al., 2000). Per unit area of substrate we have $G_{v s}=\beta_{v s} R_{n}(0)$ and $G_{b s}=\beta_{b s} R_{n}(0), \beta_{v s}$ and $\beta_{b s}$ representing the proportions of residual net radiation conducted into the soil. Available energy 


$$
A_{b s}=F_{b s}\left[R_{n}(0)-G_{b s}\right]=F_{b s}\left(1-\beta_{b s}\right) \exp \left(-c L A I_{f} / \sqrt{2 \cos \left(\phi_{s}\right)}\right) R_{n},
$$

333 and consequently

$$
A=R_{n}-G=R_{n}\left[1-\exp \left(-c L A I_{f} / \sqrt{2 \cos \left(\phi_{s}\right)}\right)\left(F_{v s} \beta_{v s}+F_{b s} \beta_{b s}\right)\right] .
$$

\subsubsection{Net radiation estimation}

The evaporation formulations detailed in Section 2.2.1 consider that the net radiation

340 of the whole surface constitutes an input to the model. It is expressed as

$$
R_{n}=(1-a) R_{g}+\varepsilon\left(R_{a t m}-\sigma T_{R}^{4}\right)
$$

344 where $a$ is the effective surface albedo, $R_{g}$ the incoming shortwave or solar radiation, $R_{a t m}$ the downward longwave or atmospheric radiation, $\varepsilon$ the surface longwave emissivity, $\sigma$ the

346 Stefan-Boltzmann constant and $T_{R}$ the composite radiometric temperature of the surface (main

347 foliage and substrate).

Net radiation, however, is not commonly and routinely measured. Given that the purpose of this work is to develop an operational and dynamic version of the model running with meteorological inputs, $R_{n}$ should be determined beforehand. If $R_{g}$ is generally measured and $R_{\text {atm }}$ measured or easily calculable from air temperature and humidity, $T_{R}$ is an unknown variable which cannot be considered as an input to the model. It can be expressed as a

353 function of the component temperatures in the following way based on the Stefan-Boltzmann 354 law (Norman et al., 1995):

$$
T_{R}=\left[f_{0} T_{f}^{4}+\left(1-f_{0}\right) T_{s}^{4}\right]^{1 / 4}
$$

358 where $T_{f}$ is the temperature of the main foliage and $T_{s}$ is the composite substrate temperature expressed as a weighted mean of the component temperatures 


$$
f_{0}=1-\exp \left(-c L A I_{f}\right)
$$

367 with $c$ the same coefficient as in Eq. (7) and $L A I_{f}$ the leaf area index of the main foliage. 368 Given that surface temperature $T_{R}$ is required to solve Eq. (12), an iterative procedure is implemented to obtain the corresponding surface temperatures $\left(T_{f}, T_{v s}, T_{b s}\right)$. An initial loop sets $T_{i}=T_{a}(i=f, v s, b s)$ to solve Eqs. (12) to (15) and to calculate the distribution of available energy from Eqs. (7) to (11). Eqs. (4) to (6) are then used to calculate $\lambda E_{t}$ and $D_{m}$, which allows calculating a new set of component surface temperatures $T_{i}$, which are reintroduced into Eq. (13) until the convergence is achieved. The details of surface temperatures 374 calculation are presented in Appendix B.

The effective albedo for shortwave radiation ( $a$ in Eq. (12)) is obtained using the

$$
a=f_{0} a_{f}+\frac{a_{s}\left(1-f_{0}\right)^{2}}{\left(1-f_{0} a_{f} a_{s}\right)},
$$

380 where $a_{f}$ and $a_{s}$ are the albedos of the main foliage and of the substrate, respectively. Substrate

381 albedo $a_{s}$ is calculated as a simple weighted component albedo: $a_{s}=F_{b s} a_{b s}+F_{v s} a_{v s}$, with $a_{v s}$ 382 and $a_{b s}$ the albedo of the vegetated and bare soil, respectively.

2.2.4 Parameterizations of surface and aerodynamic resistances

\section{Surface resistances}

The main foliage surface resistance to vapor transfer is parameterized using the widely used Jarvis-type analytical formulation (Jarvis, 1976). This formulation links the stomatal conductance (inverse of resistance) to environmental factors controlling the relative stomatal closure: photosynthetically active radiation $\left(P A R_{f}\right)$, vapor pressure deficit $\left(D_{a}\right)$ and soil water 


$$
g_{s, f}=1 / r_{s, f}=\left(g_{x, f} L A I_{f}\right) f_{1}\left(P A R_{f}\right) f_{2}\left(D_{a}\right) f_{3}\left(\theta_{f}\right),
$$

where $g_{x, f}$ is the maximum leaf stomatal conductance, observed when environmental factors

397 are not limiting. Each function represents a stress function with values between 0 and 1 . They 398 are defined as

$$
f_{1}\left(P A R_{f}\right)=1-\exp \left(-P A R_{f} / K_{1}^{f}\right)
$$

404 where $P A R_{f}$ is the photosynthetically active radiation reaching the main foliage (calculated as a fraction of solar radiation); $K_{1}^{f}$ and $K_{2}^{f}$ are two empirical parameters. The stress function

406 for soil water content is parameterized considering a negative exponential relationship 407 between stomatal conductance and soil water deficit (Stewart, 1988). This relationship is 408 defined as

$$
f_{3}\left(\theta_{f}\right)=1-\exp \left[-K_{3}^{f}\left(\theta_{f}-\theta_{f, w p}\right)\right]
$$

412 with $\theta_{f}$ the volumetric soil moisture averaged over the depth of the rooting system, $\theta_{f, w p}$ its

413 moisture at wilting point and $K_{3}^{f}$ a fitting parameter.

414 Grass cover conductance is calculated using the same formulation as above (subscript

$415 f$ is replaced by subscript $v s$ ), but with specific parameters and coefficients. However, since 416 grass occupies only a portion of the representative area $\left(F_{v s}\right)$, the stomatal conductance should 417 be multiplied by this relative area (Lhomme et al., 2012). Local observations indicate that the 418 inter-row grass cover extends its vegetative cycle until early summer and then completely 419 dries out, which means that stomatal conductance becomes equal to zero and only soil 420 evaporation should be considered, then $F_{v s}$ is set to zero.

421 Direct evaporation from topsoil layers is regulated by complex processes that can be 422 summarized in a soil surface resistance $r_{s, b s}$. A wide list of formulations for this physical 
423 control on evaporation can be found in the literature, most of them relating $r_{s, b s}$ to local

424 observations of soil water content (e.g. Mahfouf and Noilhan 1991). This resistance was

425 parameterized using the formulation proposed by Sellers et al. (1992), divided by bare soil 426 relative area:

$$
r_{s, b s}=\exp \left(A_{1}-B_{1} \theta_{b s} / \theta_{s, b s}\right) / F_{b s}
$$

430 with $\theta_{b s}$ and $\theta_{s, b s}$ the actual and saturated water content of the upper soil layer; $A_{1}$ and $B_{1}$ are

431 fitting parameters.

\section{Aerodynamic resistances}

The aerodynamic resistance between canopy source height $\left(z_{m}\right)$ and reference height $436\left(z_{r}\right)$, assumed to be the same for heat and water transfer, is calculated using the formulation 437 proposed by Brutsaert (1982), which takes into account the stability correction functions for 438 momentum and heat under non-neutral conditions. The boundary layer resistance of the main 439 foliage is estimated using the formulation proposed by Choudhury and Monteith (1988). The 440 aerodynamic resistances between the substrate and the mean canopy source $\left(r_{a, v s}\right.$ and $\left.r_{a, b s}\right)$ are 441 defined by the integral of the inverse of the eddy diffusivity (Choudhury and Monteith, 1988; 442 Shuttleworth and Gurney, 1990). All these aerodynamic resistances are detailed in Appendix 443 C. For substrate components, the aerodynamic resistances should be weighted by their relative 444 area, as highlighted by Lhomme et al. (2012). If $r_{a, i}^{1}(i=v s, b s)$ is the aerodynamic resistance 445 per unit area of component substrate with relative area $F_{i}$, the aerodynamic resistance per unit 446 area of land surface should be written as $r_{a, i}=r_{a, i}^{1} / F_{i}$.

\subsection{Water balance model}

To simulate the water budget seasonal dynamics, the evaporation model described in 453 section 2.2, which is run with an hourly time step, is coupled with a soil water balance module 454 run with a daily time step. The daily time step was selected for feasibility reasons, since daily 
values of rainfall are usually more available than hourly values. The soil layer beneath the vegetation is divided into three finite reservoirs (Fig. 1): a reservoir (1), located just below the bare soil component with relative area $F_{1}=F_{b s}$ and depth $z_{1}$; reservoir (2), located just below the vegetated soil with relative area $F_{2}=F_{v s}$ and depth $z_{2}$; and reservoir (3), located below reservoirs (1) and (2), which extends to a depth $z_{R}$ taken as equal to the vines rooting depth.

460 Available water content of each soil compartment is considered as uniformly distributed over

461 the corresponding soil profile. Bare soil and vegetated soil evaporation occur respectively

462 from reservoir 1 and 2. Main foliage is supposed to extract water both from reservoirs 2 and 3, because the rooting system of vines is expected to extend within that of grass. A saturated zone with depth $z_{G}$ is also considered, which potentially can rise to reach the bottom of reservoir (3).

Horizontal water transfers, as well as surface runoff, are considered out of the scope of this one-dimensional modeling approach and are ignored. In any case, the runoff component can be added (or subtracted) to the infiltration term of the water balance. Thus, the main water input to the system corresponds to the infiltration of water from precipitation to reservoirs (1) and (2). Root water uptake by the vineyard and grass, and bare soil evaporation correspond to the main water outputs. Transfers from reservoirs (1) and (2) to (3), and from (3) to the saturated zone are carried out through percolation process. Capillary rise from the saturated zone to reservoir (3) can also act as a secondary input of water. Capillary rise from reservoir (3) to surface reservoirs (1) and (2) is assumed to be negligible.

Soil water capacity $\operatorname{TSW}_{i}$ (total soil water) for each reservoir is defined as the difference between the amount of water stored at field capacity and a minimum amount,

$$
T S W_{i}=1000 F_{i} z_{i}\left(\theta_{f c, i}-\theta_{n, i}\right)\left(1-p_{i}\right), \quad i=1 \text { or } 2
$$

$$
T S W_{3}=1000\left[F_{2}\left(z_{R}-z_{2}\right)+F_{1}\left(z_{R}-z_{1}\right)\right]\left(\theta_{f c, 3}-\theta_{n, 3}\right)\left(1-p_{3}\right),
$$

$483 T S W_{i}$ is expressed in $\mathrm{mm}$ and the reservoir depth $z_{i}$ in $\mathrm{m}, \theta_{i}$ is the volumetric humidity in $484 \mathrm{~m}^{3} \mathrm{~m}^{-3}$ (subscript $f_{c}$ indicates field capacity and $n$ a minimum value), $p_{i}$ is the fractional stone 485 content, and the value 1000 is a conversion factor. Similarly, available soil water $\left(A S W_{i}\right)$ of 486 each reservoir is defined as the difference between its actual water content $\left(\theta_{i}\right)$ and its content 487 at a minimum value $\left(\theta_{n, i}\right)$. It is expressed by the same equations as (22) and (23), where $\theta_{f c, i}$ is 
488 replaced by $\theta_{i}$. For reservoir (2) the minimum humidity $\left(\theta_{n, 2}\right)$ is taken to be equal to that at 489 wilting point $\left(\theta_{v s, w p}\right)$. For reservoirs (1) and (3), the minimum humidity $\theta_{n, i}$ is set to minimum 490 values below wilting point, as observed by Trambouze and Voltz (2001) on the same plot 491 (Table 2).

492 The root system of the main vegetation is supposed to extract water from 493 compartments (1) and (2). The grass cover extracts water only from reservoir (2) and bare soil 494 evaporation comes from reservoir (1) which is only a few centimeters deep. The amount of 495 water $\left(A S W_{i}\right)$ stored into each of the three compartments is calculated following a dynamic process with a daily budget (subscript $j$ ):

$$
A S W_{1, j}=A S W_{1,(j-1)}+I_{1, j}-E_{1, b s, j}-D_{1, j},
$$

$$
A S W_{2, j}=A S W_{2,(j-1)}+I_{2, j}-E_{2, v s, j}-E_{2, f, j}-D_{2, j}
$$

$$
A S W_{3, j}=A S W_{3,(j-1)}+I_{3, j}+C R_{3, j}-E_{3, f, j}-D_{3, j} .
$$

The infiltration terms are denoted by $I$, the percolation terms by $D$ and the evaporation terms by $E$. All the terms are expressed in $\mathrm{mm} \mathrm{d}^{-1}$. The water inputs for vegetated and bare soil reservoirs are daily rainfall $\left(P_{j}\right)$ weighted by their relative area $\left(F_{i}\right)$, so $I_{i, j}=F_{i} P_{j}(i=1$ and $2)$. The infiltration into the third reservoir $\left(I_{3, j}\right)$ is expressed as the sum of the drainage components of the upper reservoirs as $I_{3, j}=D_{1, j}+D_{2, j}$. For each reservoir, percolation is

509 calculated as the amount of water in excess with respect to the total available water: it is the positive difference between the sum of inputs and the water holding capacity of the reservoir defined as the difference between $T S W_{i}$ and $A S W_{i}$. For the surface compartments ( $i=1$ and 2)

512 we have

$$
D_{i, j}=I_{i, j}-\left(T S W_{i}-A S W_{i, j}\right) \quad \text { if } \quad I_{i, j}>\left(T S W_{i}-A S W_{i, j}\right),
$$

518 and for compartment (3) 
$D_{3, j}=\left(D_{1, j}+D_{2, j}\right)-\left(T S W_{3}-A S W_{3, j}\right) \quad$ if $\quad\left(D_{1, j}+D_{2, j}\right)>\left(T S W_{3}-A S W_{3, j}\right)$,

Given that the evaporation module is run with a time step shorter than one day (e.g. 1

527 simple weighting by the relative soil water content of these two compartments.

528 Putting $A S W_{f}=A S W_{2}+A S W_{3}$, we have respectively

$$
E_{2, f, j}=\frac{A S W_{2}}{A S W_{f}} \sum_{h=1}^{24} E_{f, j, h} \quad \text { and } \quad E_{3, f, j}=\frac{A S W_{3}}{A S W_{f}} \sum_{h=1}^{24} E_{f, j, h} \text {, }
$$

532 where $E_{f, j, h}$ is the evaporation from the main foliage in $\mathrm{mm} \mathrm{h}^{-1}$. In Eq. (31), evaporation components $E_{f,}, E_{v s}$ and $E_{b s}$ are obtained by Eqs. (2) and (3).

Since the main foliage extracts water from compartments (2) and (3), the soil water content $\left(\theta_{f}\right)$ involved in its stress function (Eq. (20)) is calculated as the mean of the water contents of both compartments weighted by their relative volume:

$$
\theta_{f}=\frac{V_{2} \theta_{2}+V_{3} \theta_{3}}{V_{2}+V_{3}}
$$

540 where the volumes of compartments (2) and (3) are calculated respectively as $V_{2}=F_{v s} z_{2}$ and

$541 V_{3}=F_{b s}\left(z_{R}-z_{1}\right)+F_{v s}\left(z_{R}-z_{2}\right)$. The stress function for the vegetated soil simply involves $\theta_{v s}=$ $542 \theta_{2}$.

The upward flow of groundwater to the root zone by capillary rise is driven by the soil

547 hydraulic properties, the vertical gradient of water potential and the depth of the saturated 548 zone (Maxwell and Miller, 2005; Vervoort and van der Zee, 2008), with high nonlinearities involved (Bogaart et al., 2008). When the water table is shallow, the increase in soil moisture 
550 of the root zone induced by the upward flow from the saturated zone can directly influence 551 the magnitude and seasonal course of evaporation (Guix-Hébrard et al., 2007; Soylu et al., 552 2011). In the present work, the upward transfer of water by capillary rise $\left(C R_{3}\right)$ from the 553 saturated zone to reservoir (3) is estimated using a bulk form of Darcy's law, which considers 554 the flow of water proportional to the difference of water potential and inversely proportional 555 to the distance between reservoirs

$$
C R_{3}=K_{G, 3}\left(\frac{\Psi_{s, G}-\Psi_{3}}{\Delta z_{G, 3}}\right),
$$

559 where $\Psi_{s, G}$ is the water potential of the saturated zone (Clapp and Hornberger, 1978), $\Delta z_{G, 3}$ is

560 the distance between the top of the saturated zone $\left(z_{G}\right)$ and the bottom of reservoir (3) $\left(z_{R}\right)$, 561 and $K_{G, 3}$ the soil hydraulic conductivity of the transition zone between $z_{G}$ and $z_{R}$ (Fig. 1). The 562 water potential of unsaturated soil is the sum of pressure potential and gravitational potential 563 taking the reference height at water table level $\Psi_{3}=\Psi_{p, 3}+\left(z_{G}-z_{R}\right)$. Pressure potential $\Psi_{p, 3}$ 564 and hydraulic conductivity are determined as a function of soil water content $\theta_{3}$ following 565 Campbell (1974) and Clapp and Hornberger (1978)

$567 \quad \Psi_{p, 3}(\theta)=\frac{\Psi_{s, 3}}{\left(\theta_{3} / \theta_{s, 3}\right)^{b_{3}}}$,

569 where the parameters $\Psi_{s, 3}, \theta_{s, 3}$ (water potential and soil water content for saturated

570 conditions) and $b_{3}$ (a pore size distribution index) are given by Clapp and Hornberger (1978) 571 according to soil properties. The unsaturated hydraulic conductivity of the transition zone $572\left(K_{G, 3}\right)$ between the top of the water table and the bottom of reservoir (3) is a power function of 573 soil moisture content of this transition zone between $z_{R}$ and $z_{G}$ (Campbell, 1974). Since this 574 moisture content is a priori unknown, the same value as reservoir (3) is considered

$$
K_{G, 3}=K_{s, 3}\left(\frac{\theta_{3}}{\theta_{s, 3}}\right)^{2 b_{3}+3},
$$


$578 K_{s, 3}$ is the hydraulic conductivity under saturated conditions. Finally, Darcy's law can be

579 rewritten in a bulk form as

$$
C R_{3}=K_{G, 3}\left[\left(\frac{1}{z_{G}-z_{R}}\right)\left(\Psi_{s, G}-\frac{\Psi_{s, 3}}{\left(\theta_{3} / \theta_{s, 3}\right)^{b_{3}}}\right)-1\right],
$$

583 where $\Psi_{s, G}$ is the water potential of the saturated zone (Clapp and Hornberger, 1978), the

584 values of $\theta_{3}$ being given by the soil water balance model at each time step.

\section{Experiment and model implementation}

\subsection{Study area}

The experiment took place in the vineyard watershed of the Peyne river, a tributary of

the Hérault river, located in the Languedoc-Roussillon region of southern France. The climate is Mediterranean, with an average annual precipitation of $650 \mathrm{~mm}$, mainly concentrated during autumn and spring, and a dry summer season. Average annual reference evaporation is $1105 \mathrm{~mm}$. Soil was a Cambisoil (clayic) with a 2.3 to $2.5 \mathrm{~m}$ depth. located at $43.4739^{\circ} \mathrm{N} 3.3697^{\circ} \mathrm{E}$, with an elevation of 42 m.a.s.l. The inter-row distance was $2.5 \mathrm{~m}$ and intra-row plant distance was $1 \mathrm{~m}$. Vine canopy height and width was maintained at $1.5 \mathrm{~m}$ and $1 \mathrm{~m}$, respectively, by regular thinning. The maximum value of vine $L A I_{f}$ was 3 . The natural grass cover is characterized by a fractional area $F_{v s}=0.3$ and $C L A I_{v s}=2$ (Paré, 2011).

\subsection{Data collection}

604 rainfall were continuously obtained from a CIMEL Enerco 400, following meteorological 605 standards, apart from wind speed (measured at $2 \mathrm{~m}$ height rather than $10 \mathrm{~m}$ for agrometeorological purposes). This weather station was located $4.4 \mathrm{~km}$ east-northeast of the vineyard. 
610 USA), a fast hygrometer KH20 (Campbell Inc., USA) and a net radiometer NRlite (Kipp611 Zonen, NLD), installed at $2.8 \mathrm{~m}$ above ground. An air temperature and relative humidity 612 probe HMP45C (Campbell Inc., USA) allowed correcting for the calibration drift of the 613 KH20. Three soil heat flux plates HFP01 (Huskeflux, NLD) were installed at $0.05 \mathrm{~m}$ below 614 the soil surface. This flux station was installed 10 times ( 3 in 2007, 7 in 2008) in the middle 615 of the vineyard, for 2-4 days periods. Raw data Eddy Covariance (EC) (wind speed 616 components, air temperature and humidity) were acquired at $20 \mathrm{~Hz}$. Other data were acquired 617 at $1 \mathrm{~Hz}$ and stored as 15 minutes averages.

618 Soil moisture data were obtained from a Vectra 503-DR CPN Neutron Probe (NP) 619 device. Soil moisture profile was sampled every $0.2 \mathrm{~m}$ between 0.2 and $2.5 \mathrm{~m}$ of soil depth. 620 This was performed biweekly and after significant rainfall events. The top $0.15 \mathrm{~m}$ layer was 621 monitored using a Soil Moisture Equipment TRASE 6050 Time Domain Reflectometry

622 sensor. Soil physical properties measured along the soil profile were averaged and weighted 623 by the corresponding horizon thickness in order to obtain a single value of actual water 624 content $(\theta)$, wilting point $\left(\theta_{w p}\right)$, field capacity $\left(\theta_{f c}\right)$, stone content $(p)$ and constants for each reservoir. Manual piezometric measurements conducted concurrently to the soil moisture profiles demonstrated the absence of watertable in the first four meters.

Vines were monitored for height and leaf area was estimated during the period of 628 maximum growth using hemispherical photographs processed using the CAN_EYE software. 629 Further details on this experiment can be found in Galleguillos et al. (2011).

\subsection{Model forcing}

In context of developing a versatile and parsimonious SVAT model devoted to the

634 characterization of vineyard water consumption, the required forcing data are conventional 635 meteorological observations such as those collected during the experiment (air temperature, 636 relative humidity, global radiation, wind speed and daily-accumulated rainfall, see Section 637 3.2). Atmospheric radiation is estimated from available meteorological data through the 638 parameterization proposed in Appendix D, but direct measurements can be used when 639 existing.

640 The leaf area index of the vine foliage $\left(L A I_{f}\right)$ is required as input variable in several 641 parameterizations (i.e. available energy components, air and surface resistances), whereby a 642 time series of $L A I_{f}$ is required. The seasonal evolution of $L A I_{f}$ is simulated as a function of 643 thermal time by means of a double logistic relationship (Clevers et al., 2002; Fisher et al., 
644 2006). In this approach, $L A I_{f}$ rises up to a plateau and then decreases when senescence begins 645 (Fig. 2k-21). It is calculated as

$$
L A I_{f}(T T)=\left(L A I_{f, \text { max }}-L A I_{f, \text { min }}\right)\left(\frac{1}{1+\mathrm{e}^{m_{1}+m_{2}\left(T T-T T_{1}\right)}}-\frac{1}{1+\mathrm{e}^{m_{3}+m_{4}\left(T T-T T_{2}\right)}}\right)+L A I_{f, \text { min }},
$$

649 with $L A I_{f, \max }$ and $L A I_{f, \text { min }}$ the maximum and minimum values of $L A I_{f}$ during the growing

$$
T T=\sum \max \left(\frac{T_{\max }+T_{\min }}{2}-T_{b}, 0\right)
$$

654 where $T_{\max }$ and $T_{\min }$ are the daily maximum and minimum temperatures $\left({ }^{\circ} \mathrm{C}\right)$, respectively, 655 and $T_{b}$ a base temperature below which plant growth is negligible, considered typically as $65610^{\circ} \mathrm{C}$ for grapevine (Winkler and Williams, 1939). In Eq. (37) $m_{1}$ and $m_{2}$ are fitting 657 parameters that control the growth stage, $m_{3}$ and $m_{4}$ are those for the senescence stage, $T T_{1}$ and $T T_{2}$ represent empirical values that drive the beginning and ending of the vegetative cycle. The values of the parameters were obtained by applying a basic fitting procedure considering

660 the vegetation data collected over the 2008 season: the value of $L A I_{f \text {, max }}$ and the observed 661 dates of three foliage stages (beginning of growth, maximum growth and beginning of 662 senescence). The thermal summation began from 01-March-2008 (taking $L A I_{f, \min }=0$ ) and 663 the values found were: $T T_{1}=800, T T_{2}=2500, m_{1}=0.01, m_{2}=0.07, m_{3}=0.01$ and $m_{4}=0.05$.

664 The grass cover is assumed to be already green and covering at the beginning of the 665 seasonal cycle and to be completely senescent if a dry spell of seven consecutive days without 666 available soil water $\left(A S W_{2}=0\right)$ occurs (Paré, 2011). When this event occurs, only bare soil evaporation is considered during the following days $\left(F_{v s}=0\right)$. Local observations suggest that the grass cycle restarts after the grape harvest.

\subsection{Model calibration}

As for most SVAT models, the correct implementation of the three-source model 673 described above depends upon the appropriate specification of the controlling parameters.

674 They are often difficult to obtain empirically by local fitting and a wide variation in their 
675 values is found in the literature. Moreover, their transferability to different environmental conditions should be handled with care at the risk of systematic errors.

In the present work, a total of 31 parameters have to be defined first. Given the wide

678 range of values found in the literature and the lack of local observations, a total of 16 679 parameters related to energy balance and surface resistances (listed in Table 1) were obtained 680 by calibration, whereas a total of 15 soil-related parameters were obtained by local 681 observation (soil profile description) or direct consultation of the literature in the case of 682 capillary rise equations (Table 2). The calibrated parameters were calculated by applying the Multi-objective Calibration Iterative Procedure (MCIP) algorithm developed by Demarty et al.

684 (2004, 2005). This multi-criteria global calibration method is based on the minimization of a cost function describing the model performance in relation to field observations. Thus, 686 starting from an initial uncertainty range for each parameter (Table 1), an iterative procedure 687 is carried out to reduce the feasible parameter space by optimization of model outputs against 688 observations. Bastidas et al. (1999), Gupta et al. (1999) and Demarty et al. (2004, 2005) provide detailed description of this multi-objective calibration approach, and several works in land-surface models calibration have used this stochastic method, namely Coudert et al. (2006), Saux-Picart et al. (2009) and Guillevic et al. (2012).

In an algorithmic way, for each iteration, the MCIP method can be summarized as follows: (1) based on local measurements and literature, the initial feasible parameter space is defined (Table 1); (2) the parameter space is uniformly sampled and a set of Monte Carlo random simulations is performed for each parameter combination (2000 in our case); (3) the corresponding cost functions are calculated for every single simulation, in this case using the root mean square errors (RMSE ${ }^{\dagger}$ ) between model estimates and observed values; (4) using the Pareto ranking approach, or a simple sorting when only one objective function is calculated,

699 the resulting cost function ensemble is partitioned into acceptable and non-acceptable 700 solutions according to a prescribed cost functions threshold; (5) a sensitivity analysis of 701 model parameters is performed based on the MOGSA algorithm (Bastidas et al., 1999), which 702 consists in carrying out the non-parametric test of Kolmogorov-Smirnov to statistically compare the empirical cumulative distribution of model parameters between the acceptable 704 and non-acceptable solutions; and (6) the parameter space is contracted for those parameters 705 with significant differences between the two samples (i.e. sensitive parameters) found in (5),

$+\operatorname{RMSE}=\sqrt{\sum_{1}^{n}\left(e_{i}-m_{i}\right)^{2} / n}$, with $e_{i}$ the estimated value and $m_{i}$ the observed value at time step $i$ 
and then a new set of simulations is performed. Parameters found as no sensitive are left to vary freely in the a priori uncertainty range of the precedent iteration. These steps are executed iteratively (10 iterations in our case) in order to narrow the parameter range until an optimized set of parameters is obtained.

In the present work, this methodology was applied to obtain an optimized set of parameters belonging to the plant-atmosphere module (Table 1), soil parameters being set as constant during the calibration procedure (Table 2). In this way, total latent heat flux was simulated and the cost function (RMSE) was minimized for a total of eight selected days where both evaporation and soil water content measurements were available. Initial soil water content of the three reservoirs was set by correcting the first observed value by the cumulative evaporation of the previous days.

\section{Results}

The simulation period is constrained by the data availability, comprising the growing season from 25-July through 30-September in 2007 and from 10-April through 30-September in 2008. The time series of meteorological data used for model forcing during the simulation period are shown in Fig. $2 \mathrm{a}-2 \mathrm{j}$. The time series of $L A I_{f}$ obtained with Eq. (37) and CLAI $I_{v s}$, both used for model forcing, are shown in Fig. 2k-21. Local information from growers indicates that, given vineyard pruning, $L A I_{f, \max }$ can be taken as the same for 2007 and 2008 seasons, so the same curve was used in both simulation periods. A contrasting soil water recharge was observed during these two periods: the 2007 season was characterized by dryer conditions, with $262 \mathrm{~mm}$ (versus $321 \mathrm{~mm}$ in 2008) of cumulated rainfall from April through September. Furthermore, the fall and winter precipitations preceding the vineyard growing seasons provided a lower load in 2007 than in 2008: $173 \mathrm{~mm}$ versus $306 \mathrm{~mm}$ from October to March.

In the first part of this section, the values of the parameters obtained with the MCIP algorithm are presented and analyzed. The second part addresses the validation of the diurnal course of hourly evaporation derived from the surface energy balance module only, as forced with measurements of net radiation and soil moisture. In the third part, the whole model, including both the surface energy balance and the soil water balance, is validated on simulations of water balance at a daily time step. Finally, the model versatility is explored by analyzing the impact of capillary rise and vineyard structure on total evaporation and soil 
water balance.

\subsection{Analyzing calibrated parameters}

The values of the parameters of the plant-atmosphere module inferred from the MCIP

744 algorithm are shown in Table 1. There are two types of parameters: a set of biophysical parameters obtainable from measurements and another one corresponding to fitting empirical coefficients. Checking the pertinence and accuracy of the first set of optimized values is necessary. Very few references in the literature report measurements of these parameters for vineyards.

The attenuation coefficient of the vineyard foliage for net radiation $c=0.45$ was obtained by the MCIP algorithm. In the literature there is a large range of values for this parameter. Sene (1994) proposed $c=0.68$ for a different type of vineyard grown in southern Spain and characterized by free standing bushes with a higher aerial biomass. This value was also used by Zhang et al. (2008) in China. The value $c=0.38$ was obtained by PobleteEcheverria and Ortega-Farias (2009) and $c=0.5$ by Ortega-Farias et al. (2007) for vineyards in central Chile. These last values are closer to that found here $(c=0.45)$, likely due to a higher similarity with the vineyards trained in trellis system for the same variety under Mediterranean-type conditions.

The maximum stomatal conductance calculated by the MCIP algorithm was $g_{x, f}=$ $3.3 \times 10^{-3} \mathrm{~m} \mathrm{~s}^{-1}$. This value is fairly realistic since it is within the range of values measured by Winkel and Rambal (1990) $\left(1.25 \times 10^{-3} \mathrm{~m} \mathrm{~s}^{-1}\right)$, Lebon et al. (2003) $\left(2.86 \times 10^{-3} \mathrm{~m} \mathrm{~s}^{-1}\right)$, Zhang et al. (2008) $\left(6.85 \times 10^{-3} \mathrm{~m} \mathrm{~s}^{-1}\right)$, Ortega-Farias et al. (2010) $\left(6.94 \times 10^{-3} \mathrm{~m} \mathrm{~s}^{-1}\right)$ and also close to the daytime average value found by Ortega-Farias et al. (2007) on irrigated vineyard $\left(2.13 \times 10^{-3} \mathrm{~m}\right.$ $\left.\mathrm{s}^{-1}\right)$. Also, Jones et al. (2002) found an average $g_{x, f}=4.0 \times 10^{-3}$ between shaded and sunlit leaves in irrigated vineyard. For the grass cover, its Mediterranean type can explain the lower value retrieved for its maximal stomatal conductance $g_{x, v s}$ than the daytime average value of Allen et al. (1989) $\left(g_{x, v s}=1.0 \times 10^{-2} \mathrm{~m} \mathrm{~s}^{-1}\right)$.

The relatively large dispersion observed in the measured values of $g_{x, f}$ and $c$ reveals the difficulty to find adequate values for model parameters and justifies the use of a stochastic approach. Conversely, a smaller variability is observed for vineyard albedo. The optimized

770 value $a_{f}=0.24$ is close to those found by Sene et al. (1994) ( $a_{f}=0.27$ ), Pieri and Gaudillère 771 (2003) $\left(a_{f}=0.2\right)$ and Ortega-Farias et al. (2010) $\left(a_{f}=0.19\right)$. On the other hand, optimized 772 substrate albedos $\left(a_{b s}=0.3\right.$ and $\left.a_{b s}=0.25\right)$ are very close to those often found in the literature 
773 for dry and grassed soils (e.g. Idso et al., 1975; Grasser and van Babel, 1982; Davies, 2006).

774 The differences are ascribed to different substrate composition.

Finally, when dealing with soil heat flux estimation, the retrieved fraction $\beta_{b s}$ for bare soil is higher than $\beta_{v s}$ for vegetated soil, which is in agreement with the thermal properties of

777 both covers.

\subsection{Evaporation estimates}

In this section, the evaporation model is evaluated alone, without being coupled with

the soil water balance module. Measurements of soil water content and net radiation are used as input data for Eq. (20) and Eqs. (7) to (11), respectively, in order to evaluate the threesource scheme itself, independently of its operational utilization on a seasonal basis. The model performance in terms of simulated daily course of total evaporation is compared against a set of EC measurements during the contrasting environmental conditions of 2007 and 2008, which constitutes an assessment of the residual calibration error. A comparison between the SVAT model outputs and the set of hourly EC measurements is shown in Fig. 3, including the agreement evaluation by using the root mean square error (RMSE), the bias estimation $\left(\mathrm{B}^{\ddagger}\right)$ and the coefficient of determination $\left(R^{2}\right)$. A quite reasonable agreement between estimated and measured evaporation rates was obtained at the hourly timescale with 792 a high linear representation $\left(R^{2}=0.95\right)$.

Fig. 4 shows the diurnal variation of evaporation simulated by the model compared to

794 EC data for eight distinct days. A good agreement is observed between the daily cycle of model estimates and EC measurements in spite of a slight overestimation on 14-Jun-2008 and a minor underestimation at the end of the 2008 season (09-Aug-2008). The strong soil water content depletion during 2007 is evidenced through a significant reduction in $\lambda E_{t}$ (Figs. 4a-4c), despite the almost constant $L A I_{f}$ (Fig. 2k). In 2008, the initial growing period (Fig. 4d) is characterized by the low foliage area of the vines $\left(L A I_{f}=0.7 \mathrm{~m}^{2} \mathrm{~m}^{-2}\right)$, when $\lambda E_{t}$ emanates mainly from bare and vegetated soils. When vine $L A I_{f}$ increases, its transpiration increases leading to maximum values of latent heat flux around $250 \mathrm{~W} \mathrm{~m}^{-2}$ (Figs. 4f-4g). During the two periods shown in Figs. $4 \mathrm{f}$ and $4 \mathrm{~g}$, when vine foliage is fully developed ( $L A I_{f}$ close to 3 ),

803 the agreement between the two $\lambda E_{t}$ series is rather good. This period of the growing season 804 can be considered as the most important from an agricultural point of view, given the impact

$\pm \mathrm{B}=\sum_{1}^{n}\left(e_{i}-m_{i}\right) / n$, with $e_{i}$ the estimated value and $m_{i}$ the observed value at time step $i$ 
of water stress on grape production (Schultz, 1996).

\subsection{Seasonal dynamics of water balance}

In this section, the evaporation model is coupled with the soil module to jointly

810 simulate the seasonal dynamics of total evaporation $\left(E_{t}\right)$ and soil water content. $E_{t}$ is obtained

811 from Eq. (4) using the simulated soil water content $\theta$ to solve Eq. (20). The water table being 812 fairly deep (down to $4 \mathrm{~m}$ ) during the simulation period, the impact of capillary rise is

813 considered as negligible and the corresponding module is shutdown. In addition, the iterative

814 approach presented in Section 2.2.3 is used to obtain the net radiation. It yields relatively 815 good estimates, compared to measured values (RMSE $=46 \mathrm{~W} \mathrm{~m}^{-2}$; results not shown), but 816 with a slight overestimation, maybe explained by a higher load of atmospheric radiation

817 obtained by the scheme detailed in Appendix D, which certainly would have required a local 818 calibration (e.g. Lhomme et al., 2007).

An overall comparison between simulated and observed $E_{t}$ and $\theta$ values for both seasons is shown in Fig. 5a and 5b, respectively. The simulated value of $\theta$ is calculated as the weighted mean of the water content of each reservoir. The evaporation results show a relatively good agreement between model and EC data, with a regression slope close to 1, but some overestimation is observed. A possible explanation is the method implemented for estimating net radiation, which led to an overestimation of this input variable (bias $=+21 \mathrm{~W}$ $\mathrm{m}^{-2}$ between 07:00 and 18:00 local time), and therefore an increase of available energy for evaporation. The same comparison for $\theta$ (Fig. 5b) shows that very good estimates were obtained for both contrasting seasons.

Fig. 6 shows the time series of modeled daily evaporation and soil water content 829 during the two seasonal simulations. In general, the agreement between the simulated curves 830 and the observed data is rather good. A strong temporal decay in both evaporation and $\theta$ 831 characterizes the 2007 season, as a response of very low precipitations (Fig. 2i). For the 2008 season (Fig. 6b), the evaporation experiences a seasonal course that agree quite well with EC measurements. The seasonal evolution follows the seasonal shape of the meteorological

834 forcing and foliage development. Concerning soil water content $(\theta)$, a slight increase induced 835 by a relatively low evaporative demand and by several rainfall events (till mid-June 2008, see 836 Fig. 2j) is followed by a progressive decrease until the end of the growing season (Fig. 6d). 837 During the last part of the period (September 2008), overestimated values of $\theta$ are obtained 838 with the model, which could receive the following explanation. The dry conditions and the 
839 absence of grass cover during the last part of the growing season have induced soil crusting

840 which reduces the infiltration capacity and enhances surface runoff. Consequently, the strong

841 rainfall event just before the last measurement days (Fig. 2j), which potentially could have

842 involved important water filling for the soil, may have been lost by runoff. This phenomenon

843 was observed by Lebon et al. (2003) in the same region and also by Gaudin et al. (2010) in an

844 inter-cropping vineyard.

\subsection{Analysis of model predictions}

In order to illustrate model versatility, some static simulations were undertaken in order to examine the SVAT model under different configurations of the vineyard system and to explore the impact of crop characteristics on evaporation.

\subsubsection{Impact of capillary rise}

A simulation with constant boundary conditions was performed in order to quantify the magnitude of the water flow from the saturated zone into reservoir (3) $\left(C R_{3}\right)$. In our formulation $C R_{3}$ varies as a function of the saturated zone depth $\left(z_{G}\right)$ and the soil water content of reservoir (3) $\left(\theta_{3}\right)$. The same soil texture (clay loam) for reservoir (3) and the transition zone between $z_{G}$ and $z_{R}$ is considered and the corresponding values of hydraulic parameters taken from Clapp and Hornberger (1978) are shown in Table 2. Fig. 7 shows the predicted values of $C R_{3}$ as a function of $\theta_{3}$ and of the distance between the root zone and the water table $z_{G}-z_{R}$. As can be anticipated, capillary rise $\left(C R_{3}\right.$ value) decreases with the distance $\left(z_{G}-z_{R}\right)$ and increases with the soil water content $\theta_{3}$ in relation with the hydraulic conductivity $K_{G, 3}$. Although it was not possible to confront these values with field measurements, they are within the range of values obtained by several authors from similar or more complex approaches of capillary rise (e.g. Raes and Deproost, 2003; Bogaart et al. 2008; Vervoort et al. 2008). Our results are realistic and confirm the possible use of the capillary rise module when the water table is shallow.

\subsubsection{Impact of vineyard structure on evaporation rate}

872 the distance between rows and the relative proportion of grass $\left(F_{v s}\right)$ and bare soil $\left(F_{b s}\right)$. In 
873 order to estimate the impact of foliage surface proportion on vineyard evaporation, the concept of clumped leaf area index $\left(C L A I_{f}\right)$ is used (defined as the leaf area per unit area of substrate covered by the foliage): $L A I_{f}=F_{f} C L A I_{f}$, where $F_{f}$ is the proportion of soil surface occupied by the vine canopy. $F_{f}$ depends on the width of the vine row $\left(w_{r}\right)$ and on that of the inter-row $\left(w_{i}\right)$, and can be expressed as

$$
F_{f}=\frac{w_{r}}{w_{r}+w_{i}}=\frac{1}{1+w_{i} / w_{r}} .
$$

Inter-row width $w_{i}$ is varied maintaining $C L A I_{f}$ and $w_{r}$ fixed: 2.5 and $1 \mathrm{~m}$ respectively. In this way, total evaporation is simulated as a function of $w_{i}$ and hence $L A I_{f}$ using Eq. (39). Standard values of meteorological and soil variables were considered: $R_{n}=400 \mathrm{~W} \mathrm{~m}^{-2}, T_{a}=25{ }^{\circ} \mathrm{C}$, $D_{a}=10 \mathrm{hPa}, u_{a}=2 \mathrm{~m} \mathrm{~s}^{-1}, R_{g}=600 \mathrm{~W} \mathrm{~m}{ }^{-2}, \theta_{f}=0.3, \theta_{v s}=0.25, \theta_{b s}=0.25$. Secondly, the proportion of vegetated soil $F_{v s}$ (and consequently $F_{b s}$ ) is varied between 0 (bare soil only) and 1 (grassed soil only). The model is run by considering the combined effect of $w_{i}$ and $F_{v s}$ variations on total evaporation $E_{t}$, all other conditions being kept constant. The results of this simulation are shown in Fig. 8: for $F_{v s}=0.3$ (our experimental dataset) a decrease in $E_{t}$ of about $0.02 \mathrm{~mm} \mathrm{~h}^{-1}$ is estimated when the distance between rows $w_{i}$ varies from 0.5 to $4 \mathrm{~m}$. For $w_{i}=2 \mathrm{~m}, E_{t}$ increases of about $0.1 \mathrm{~mm} \mathrm{~h}^{-1}$ when passing from fully bare $\left(F_{v s}=0\right)$ to fully grassed soil $\left(F_{v s}=1.0\right)$, suggesting a higher sensitivity to grass cover.

\section{Discussion}

A quite good performance of the proposed SVAT model was obtained in representing

896 the seasonal water balance. Model estimates of total evaporation are quite good when 897 considering the surface energy balance module alone (Fig. 3), forced with measured net 898 radiation and soil moisture. They are less accurate when considering the coupling between 899 surface energy balance and soil water balance (Fig. 5). This is ascribed to the fact that net 900 radiation and soil moisture are simulated and not measured. Certainly, the parameterization 901 adopted for foliage surface resistance is critical. Indeed, the model was found very sensitive to 902 the stress function $f_{3}$ of Eq. (20) involving soil moisture $(\theta)$. In addition, the maximum leaf 903 conductance of grapevine $g_{x, f}$ (Eq. (17)) was found to be highly variable in the literature. It 904 might also vary in time as a function of phenological stage and environmental conditions, so 
905 that the use of a single value over the whole season might be inappropriate. Previous works

906 have shown that parameter sensitivity can vary for different periods (Demarty et al., 2005;

907 Guillevic et al., 2012) and that a period-specific calibration associated with the seasonal

908 variability in vegetation properties or rainfall should be preferable (Coron et al., 2012;

909 Gharari et al., 2013).

910 The equations used for aerodynamic resistances (Appendix C) are very common in

911 micrometeorology but they could be a source of uncertainty. Indeed, given the influence of

912 vineyard geometry on wind flow within and above the foliage, there is a gap in the current

913 parameterizations of surface aerodynamic properties of crop canopies structured in rows. In

914 this sense, the influence of wind direction and row orientation has been reported in the

915 literature. For the case of vineyards, a significant increase in drag coefficient was found by

916 Hicks (1973) and a larger turbulent intensity by Weiss and Allen (1976) when wind flows

917 perpendicular to the rows. Also, important differences were found by Riou et al. (1987) for

918 vineyard aerodynamic parameters $\left(z_{0}\right.$ and $\left.d\right)$ as a function of wind direction and row

919 orientation, and variations in measured daytime aerodynamic resistance were found by Padro

920 et al. (1994) for different wind directions likely due to variations in $z_{0}$. Recently, using Large

921 Eddy Simulation under neutral conditions, a major channeling effect between the vine rows

922 was described by Chahine et al. (2014) for row-parallel wind, increasing the spatial variability

923 in vertical wind profile and decreasing the value of aerodynamic parameters such as $z_{0}$ and $d$

924 in relation to normal and diagonal flow. They concluded that this effect may be more

925 pronounced under unstable conditions, which might be expected in Mediterranean regions

926 during the growing season. These points raise the challenge of improving the current

927 parameterizations of aerodynamic resistances including wind direction effects.

$928 \quad$ Uncertainties associated with $R_{n}$ estimates and $L A I_{f}$ simulations also play an important

929 role on the partition of available energy and on surface and aerodynamic resistances. More

930 complex models than Beer's law can be found in the literature for canopy radiative transfer

931 (Taconet et al., 1986; Braud et al., 1995). Lebon et al. (2003) stressed that a better partitioning

932 of incoming solar radiation between vines and substrate is obtained by using the model of

933 Riou et al. (1989) which involves vineyard geometrical properties. This model, only designed

934 for shortwave radiation, was later developed by Pieri (2010a, 2010b) for long-wave radiation

935 partitioning. For the specific case of row-growing crops, a comprehensive model for radiative

936 transfer and partition (short- and long-wave radiation) was recently proposed by Colaizzi et al.

937 (2012a, 2012b). Unfortunately, given the data requirements of these radiative models, their

938 implementation is rather difficult considering the scope of the present work. 
A better representation of water stress and its impact on gas exchanges might be

940 addressed by taking into account the mechanisms responsible for variations in soil water 941 distribution and root water uptake along the profile (e.g. Tuzet et al., 2003; Amenu and 942 Kumar, 2008; Siqueira et al., 2008; Volpe et al., 2013). Certainly the simplified approach 943 adopted here represents a source of uncertainty to the model, especially in relation with vine 944 roots depth, their distribution and their impacts on soil moisture dynamics. However, the 945 inclusion of soil profiles into the soil water balance module would have significantly altered the parsimonious nature of the model, and therefore its possible use at the regional extent.

Finally, it is clear that assuming a complete infiltration of rainfall can lead to some discrepancies between model outputs and observations after strong rainfall events, such as the one registered at the beginning of September 2008 (Figs. 2j, 6d). But the inclusion of runoff into the soil water budget is a quite complex issue to solve in a one-dimensional approach. The improvement of this component requires considering the horizontal heterogeneities in soil physical properties responsible for horizontal transfers and could be carried out by coupling SVAT models with spatially-distributed hydrological models (e.g. Bouilloud et al. 954 2010).

\section{Concluding remarks}

In this work, the seasonal pattern of evaporation from a grassed Mediterranean vineyard was modeled by coupling an evaporation formulation together with a reservoir-type soil water balance model. The evaporation formulation is based on a three-source model, recently revisited by Lhomme et al. (2012), where some adaptations have been made in order to use standard meteorological data as direct inputs to the model. This approach provides realistic estimates of the component evaporations emanating from the three sources (main

964 foliage, grassed and bare soil) and allows the seasonal dynamics of soil moisture to be correctly simulated. A good agreement was obtained when the seasonal course of total evaporation and soil moisture simulations were compared against ground based references during two contrasting seasons in terms of available soil water. Neglecting runoff, however, can lead to some discrepancy after strong rainfall events on dry soil: soil crusting promotes runoff and lower soil moisture recharge. This imposes limitations to the application of the model and further investigation should focus on the coupling with distributed hydrological 971 models.

972 The model versatility can be used to explore the impact of the grassed vineyard 
973 geometry on evaporation throughout the season and for different climate conditions. The

974 static simulations performed suggest that a significant impact should be expected when the 975 distance between vine rows and the fraction of grassed soil are modified.

976 Apart from the aforementioned limitations regarding the model performance, 977 uncertainties arise from the fact that a large number of parameters should be defined for the 978 controlling factors. This difficulty has been addressed by applying an optimization procedure 979 to find the optimal values of these parameters. However, these values can vary in relation 980 with grapevine phenological phases and could be improved by testing a larger number of 981 model outputs against measurements of energy and water balance.

982 Finally, another contribution of this parsimonious model is its potential use to estimate 983 water budget components at regional scale using remotely sensed data. The energy balance984 based evaporation formulation allows one to derive surface composite temperature which can 985 be compared to the satellite estimate of the corresponding radiometric temperature. Different 986 approaches have been developed to include this temperature into SVAT models through data 987 assimilation schemes in order to obtain energy balance components (Coudert et al., 2006; 988 Caparrini et al. 2008; Sini et al., 2008) or soil moisture estimates (Jones et al., 1998; Crow et 989 al., 2008).

990

991 


\section{Acknowledgements}

993

994 This study was partly supported by the French Centre National d'Etudes Spatiales 995 (CNES/TOSCA) and by the European Commission's Seventh Framework Programme 996 (FP7/2007-2013) through the 'Research Infrastructures' action under ExpeER project (grant 997 agreement $\mathrm{n}^{\circ}$ 262060). The first author acknowledges CONICYT-Chile for the doctoral grant. 998 The constructive comments and suggestions from three anonymous reviewers are highly 999 appreciated.

1000 
1002

$1003 P_{f}=r_{a} R_{v s} R_{b s} / D E$,

1004

$1005 P_{v s}=r_{a} R_{f} R_{b s} / D E$,

1006

$1007 P_{b s}=r_{a} R_{f} R_{v s} / D E$,

1008

1009 with $D E$ written as

1010

1011

$D E=R_{f} R_{v s} R_{b s}+R_{f} R_{v s} R_{a}+R_{f} R_{b s} R_{a}+R_{v s} R_{b s} R_{a}$,

1012

1013 with the coefficients $R_{i}$ being defined as

1014

$1015 R_{f}=r_{s, f}+\left(n+\frac{\Delta}{\gamma}\right) r_{a, f, h}$,

1016

$1017 R_{v s}=r_{s, v s}+\left(1+\frac{\Delta}{\gamma}\right) r_{a, v s}$,

1018

$1019 R_{b s}=r_{s, b s}+\left(1+\frac{\Delta}{\gamma}\right) r_{a, b s}$,

1020

$1021 R_{a}=r_{a}\left(1+\frac{\Delta}{\gamma}\right)$.

1022

1023

1024 Appendix B: Expressing the component surface temperatures

1025

1026 Component surface temperatures $T_{i}(i=f, v s, b s)$ are obtained by solving the energy

1027 balance for the three sources. The corresponding available energy $\left(A_{i}\right)$ is equal to the sum of 
1028 latent and sensible heat fluxes:

1029

$1030 A_{i}=\frac{\rho c_{p}}{\gamma} \frac{\left[e^{*}\left(T_{i}\right)-e_{m}\right]}{r_{s, i}+r_{a, i, v}}+\rho c_{p} \frac{T_{i}-T_{m}}{r_{a, i, h}}$,

1031

$1032 r_{a, i, v}$ and $r_{a, i, h}$ representing the air resistances respectively for water vapor and sensible heat,

$1033 T_{m}$ and $e_{m}$ the air temperature and air vapor pressure at canopy source height $\left(z_{m}\right)$, and $e^{*}\left(T_{i}\right)$

1034 the saturated vapor pressure at $T_{i}$. After linearizing $e^{*}\left(T_{i}\right)-e^{*}\left(T_{m}\right)$, Eq. (B1) is rewritten as:

1035

$1036 \quad A_{i}=\frac{\rho c_{p}}{\gamma} \frac{\left[\Delta\left(T_{i}-T_{m}\right)+D_{m}\right]}{r_{s, i}+r_{a, i, v}}+\rho c_{p} \frac{T_{i}-T_{m}}{r_{a, i, h}}$.

1037

1038

After some algebra and taking into account that $r_{a, i, v}=n r_{a, i, h}$, surface temperature can

1039 be expressed as:

1040

$1041 T_{i}-T_{m}=\frac{\left(n r_{a, i, h}+r_{s, i}\right) A_{i} / \rho c_{p}-D_{m} / \gamma}{n+\Delta / \gamma+r_{s, i} / r_{a, i, h}}$,

1042

1043 with $n=2$ for the foliage $(i=f)$ and $n=1$ for the substrate components $(i=v s, b s), T_{m}$ being

1044 obtained by $T_{m}=T_{a}+H r_{a} / \rho c_{p}$.

1045

1046

1047 Appendix C: Formulations of aerodynamic resistances

1048

1049 The aerodynamic resistance above the canopy $\left(r_{a}\right)$ is calculated using the equation that

1050 takes into account the stability correction functions for wind $\left(\Psi_{m}\right)$ and temperature $\left(\Psi_{h}\right)$

1051 (Brutsaert, 1982):

1052

1053

$\left.r_{a}=\left(\frac{1}{k^{2} u_{a}}\right)\left[\ln \left(\frac{z_{r}-d}{z_{0}}\right)-\Psi_{h}\left(\frac{z_{r}}{L}\right)\right] \ln \left(\frac{z_{r}-d}{z_{0}}\right)-\Psi_{m}\left(\frac{z_{r}}{L}\right)\right]$,

1055 where $u_{a}$ is the wind speed at reference height $z_{r}$ and $L$ is the Monin-Obukhov length. The 
canopy roughness length $z_{0}$ is determined following Choudhury and Monteith (1988):

$1058 \quad z_{0}= \begin{cases}\bar{z}_{0, s}+0.3 z_{h} X^{0.5}, & \text { if } 0<X \leq 0.2 \\ 0.3 z_{h}\left(1-\frac{d}{z_{h}}\right), & \text { if } 0.2<X<1.5\end{cases}$

1060 where $X=c_{d} L A I_{f}$, with $c_{d}=0.2$ the mean drag coefficient assumed to be uniform within the

1061 canopy and $\bar{z}_{0, s}$ the average value of substrate roughness length $(=0.0125 \mathrm{~m})$. Following the

1062 same authors the displacement height $d$ is expressed by

1063

$1064 d=1.1 z_{h} \ln \left(1+X^{0.25}\right)$,

1065

1066 where $z_{h}$ is the mean canopy height (vineyard).

1067 The aerodynamic resistance between the substrate $(i=v s$ and $b s)$ and the canopy 1068 source height $\left(d+z_{0}\right)$ is calculated (per unit area of substrate) as (Choudhury and Monteith, 1069 1988)

1070

$1071 r_{a, i}^{1}=\frac{z_{h} \exp \left(\alpha_{w}\right)}{\alpha_{w} K\left(z_{h}\right)}\left\{\exp \left[-\alpha_{w} z_{0, i} / z_{h}\right]-\exp \left[-\alpha_{w}\left(d+z_{0}\right) / z_{h}\right]\right\}$,

1072

1073 where $z_{h}$ is the height of the main foliage (vineyard), $\alpha_{w}=2.5$ (dimensionless), $z_{0, i}$ the

1074 roughness length for momentum of vegetated $\left(z_{0, v s}=0.015 \mathrm{~m}\right)$ and bare soil $\left(z_{0, b s}=0.010 \mathrm{~m}\right)$.

$1075 K\left(z_{h}\right)$ is the value of eddy diffusivity at canopy height, obtained by

1076

$1077 K\left(z_{h}\right)=\frac{k^{2} u_{a}\left(z_{h}-d\right)}{\ln \left[\left(z_{r}-d\right) / z_{0}\right]}$.

1078

1079

Foliage bulk boundary later resistance for sensible heat is expressed as (Choudhury

1080 and Monteith, 1988)

1081

$1082 \quad r_{a, f, h}=\frac{\alpha_{w}\left[w / u\left(z_{h}\right)\right]^{1 / 2}}{4 \alpha_{0} L A I_{f}\left[1-\exp \left(-\alpha_{w} / 2\right)\right]}$, 
1084 where $w$ is leaf width $(0.01 \mathrm{~m}), \alpha_{0}$ is a constant equal to 0.005 (in $\left.\mathrm{m} \mathrm{s}^{-1 / 2}\right)$ and $u\left(z_{h}\right)$ is the

1085 wind speed at $z_{h}$, obtained by

1086

$1087 u\left(z_{h}\right)=u_{a} \frac{\ln \left[\left(z_{h}-d\right) / z_{0}\right]}{\ln \left[\left(z_{r}-d\right) / z_{0}\right]}$.

1088

1089

1090 Appendix D: Estimating atmospheric radiation

1091

1092 The incoming longwave radiation $\left(R_{a t m}\right)$ was parameterized using a formulation

1093 including both the effects of clear and cloudy sky conditions on $R_{\text {atm }}$. Several methods have

1094 been developed to estimate this component of radiative budget, which are often based on

1095 empirical formulations depending on air temperature and humidity (e.g. Brunt, 1932; Idso and

1096 Jackson, 1969; Duarte et al., 2006). In the present study the Brutsaert (1975) formulation was

1097 used to calculate the clear sky atmospheric radiation which is expressed as

1098

$1099 R_{a t m, c}=a_{1}\left(e_{a} / T_{a}\right)^{b_{1}} \sigma T_{a}^{4}$,

$1101 e_{a}$ is the actual vapor pressure $(\mathrm{Pa})$, and $a_{1}$ and $b_{1}$ are constant with values 1.24 and 0.14 ,

1102 respectively. Under cloudy sky conditions the fractional cover should be used, but this

1103 measure is very difficult to obtain in operational terms using conventional weather stations.

1104 Crawford and Duchon (1999) showed that a good estimation of sky condition could be

1105 obtained using the ratio $R_{g} / R_{0}$ between the measured solar irradiance $\left(R_{g}\right)$ and the clear-sky

1106 irradiance $\left(R_{0}\right)$. $R_{0}$ was obtained as a fraction of the extraterrestrial radiation ( $R_{\text {ext }}$, the

1107 theoretical solar radiation at the top of the atmosphere) using the formulation proposed by

1108 Allen et al. (1998):

$1110 R_{0}=R_{\text {ext }}\left(0.75+2 \times 10^{-5} Z\right)$,

1112 with $Z$ the site elevation (masl). So, considering both clear and cloudy skies conditions the

1113 downwelling longwave atmospheric radiation is estimated as (Crawford and Duchon, 1999) 
1114

$1115 \quad R_{a t m}=R_{a t m, c}\left(R_{g} / R_{0}\right)+\left(1-R_{g} / R_{0}\right) \sigma T_{a}^{4}$.

1116

1117 Since during nighttime the ratio $R_{g} / R_{0}$ cannot be calculated, Eq. (D3) was computed using

1118 the last value of $R_{g} / R_{0}$ during the previous afternoon (e.g. Lhomme et al., 2007).

1119 


\section{References}

1122 Allen, R.G., Jensen, M.E., Wright, J.L., Burman, R.D., 1989. Operational estimates of 1123 reference evapotranspiration. Agron. J. 81,650-662.

1124 Allen, R.G., Pereira, L.S., Raes, D., Smith, M., 1998. Crop evapotranspiration. FAO Irrigation 1125 and Drainage Paper 56, Rome.

1126 Amenu, G.G., Kumar, P., 2008. A model for hydraulic redistribution incorporating coupled 1127 soil-root moisture transport. Hydrol. Earth Syst. Sci. 12, 55-74.

1128 Anderson, M.A., Norman, J.M., Diak, G.R., Kustas, W.P., Mecikalski, J.R., 1997. A two1129 source time-integrated model for estimating surface fluxes using thermal infrared remote 1130 sensing. Remote Sens. Environ. 60, 195-216.

1131 Anderson, M.C., Norman, J.M., Kustas, W.P., Li, F., Prueger, J.H., Mecikalski, J.R., 2005. 1132 Effects of vegetation clumping on two-source model estimates of surface energy fluxes 1133 from an agricultural landscape during SMACEX. J. Hydrometeorol. 6, 892-909.

1134 Bastidas, L.A., Gupta, H.V., Sorooshian, S., Shuttleworth, W.J., Yang, Z.L., 1999. Sensitivity 1135 analysis of a land surface scheme using multicriteria methods. J. Geophys. Res. 104, $1136 \quad 19481-19490$.

1137 Bogaart, P.W., Teuling, A.J., Troch, P.A., 2008. A state-dependent parameterization of 1138 saturated-unsaturated zone interaction. Water Resour. Res. 44, 1-10.

1139 Bouilloud, L., Chancibault, K., Vincendon, B., Ducrocq, V., Habets, F., Saulnier, G.-M., Anquetin, S., Martin, E., Noilhan, J., 2010. Coupling the ISBA land surface model and the TOPMODEL hydrological model for Mediterranean flash-flood forecasting:

1143 Boulet, G., Chehbouni, G., Braud, I., Vauclin, M., 1999. Mosaic versus dual source 1144 approaches for modelling the surface energy balance of a semi-arid land. Hydrol. Earth $1145 \quad$ Syst. Sci. 3, 247-258.

1146 Boulet, G., Chehbouni, A., Braud, I., Vauclin, M., Haverkamp, R., Zammit, C., 2000. A 1147 simple water and energy balance model designed for regionalization and remote sensing data utilization. Agr. Forest Meteorol. 105, 117-132.

1152 Brenner, A.J., Incoll, L.D., 1997. The effect of clumping and stomatal response on 1153 evaporation from sparsely vegetated shrublands. Agr. Forest Meteorol. 84, 87-205. 
1154 Brunt, D., 1932. Notes on radiation in the atmosphere. Q. J. Roy. Meteor. Soc. 58, 389-420.

1155 Brutsaert,W.H., 1975. On a derivable formula for long-wave radiation from clear skies. Water 1156 Resour. Res. 11, 742-744.

1157 Brutsaert, W., 1982. Evaporation into the Atmosphere. Reidel Publishing Company, 1158 Dordrecht, 299 pp.

1159 Campbell, G.S., 1974. A simple method for determining unsaturated hydraulic conductivity 1160 from moisture retention data. Soil Sci. 177, 311-314.

1161 Caparrini, F., Castelli, F., Entekhabi, D., 2004. Estimation of surface turbulent fluxes through 1162 assimilation of radiometric surface temperature sequences . J. Hydrometeorol. 5, 145-159.

1163 Celette, F., Wery, J., Chantelot, E., Celette, J., Gary, C., 2005. Belowground interactions in a 1164 vine (Vitis vinifera L.)-tall fescue (Festuca arundinacea Shreb.) intercropping system: 1165 water relations and growth. Plant Soil. 276, 205-217.

1166 Celette, F., Gaudin, R., Gary, C., 2008. Spatial and temporal changes to the water regime of a 1167 Mediterranean vineyard due to the adoption of cover cropping. Eur. J. Agron. 29, 153-162. 1168 Celette, F., Ripoche, A., Gary, C., 2010. WaLIS - A simple model to simulate water 1169 partitioning in a crop association: The example of an intercropped vineyard. Agr. Water 1170 Manage. 97, 1749-1759.

1171 Centinari, M., Poni, S., Intrigliolo, D.S., Dragoni, D., Lakso, A.N., 2012. Cover crop 1172 evapotranspiration in a northeastern US Concord (Vitis labruscana) vineyard. Aust. J. 1173 Grape Wine Res. 18, 73-79.

1174 Chahine, A., Dupont, S., Sinfort, C., Brunet, Y., 2014. Wind-flow dynamics over vineyards. Bound.-Lay. Meteorol. DOI 10.1007/s10546-013-9900-4

1176 Choudhury, B.J., Monteith, J.L., 1988. A four-layer model for the heat budget of 1177 homogeneous land surfaces. Q. J. Roy. Meteor. Soc. 114, 373-398.

1178 Choudhury, B.J., 1989. Estimating evaporation and carbon assimilation using infrared 1179 temperature data: vistas in modeling. In G. Asrar (ed.), Theory and applications of optical 1180 remote sensing. Wiley, New York.

1181 Choudhury, B.J., Idso, S.B., Reginato, R.G., 1987. Analysis of an empirical model for soil 1182 heat flux under a growing wheat crop for estimating evaporation by an infrared1183 temperature based energy balance equation. Agr. Forest Meteorol. 39, 283-297.

1184 Clapp, R.B., Hornberger, G.M., 1978. Empirical equations for some soil hydraulic properties. 1185 Water Resour. Res. 14, 601-604.

1186 Clevers, J.G.P.W., Vonder, O.W., Jongschaap, R.E.E., Desprats, J., King, C., Prévot, L., 1187 Ruguier, N., 2002. Using SPOT data for calibrating a wheat growth model under 
mediterranean conditions. Agronomie 22, 687-694.

1189 Colaizzi, P.D., Evett, S.R., Howell, T.A., Li, F., Kustas, W.P., Anderson, M.C., 2012a.

1190 Radiation model for row crops: I. Geometric view factors and parameter optimization.

1191 Agron. J. 104, 225-240.

1192 Colaizzi, P.D., Scwartz, R.C., Evett, S.R., Howell, T.A., Gowda, P.H., Tolk, J.A., 2012 b.

1193 Radiation model for row crops: II. Model evaluation. Agron. J. 104, 241-255.

1194 Coron, L., Andréassian, V., Perrin, C., Lerat, J., Vaze, J., Bourqui, M., Hendrickx, F., 2012.

1195 Crash testing hydrological models in contrasted climate conditions: An experiment on

1196216 Australian catchments. Water Resour. Res. 48, W05552,

1197 doi:10.1029/2011WR011721

1198 Coudert, B., Ottlé, C., Boudevillain, B., Demarty, J., Guillevic, P., 2006. Contribution of 1199 thermal infrared remote sensing data in multiobjective calibration of a dual-source SVAT 1200 model . J. Hydrometeorol. 7, 404-420.

1201 Crawford, T.M., Duchon, C.E., 1999. An improved parameterization for estimating effective atmospheric emissivity for use in calculating daytime downwelling longwave radiation. J. Appl. Meteorol. 38, 474-480.

1204 Crow, W.T., Kustas, W.P., Prueger, J.H., 2008. Monitoring root-zone soil moisture through 1205 the assimilation of a thermal remote sensing-based soil moisture proxy into a water 1206 balance model. Remote Sens. Environ. 112, 1268-1281.

1207 Davies, J.A., 2006. A note on the relationship between net radiation and solar radiation. Q. J. 1208 Roy. Meteor. Soc. 93, 109-115.

1209 Demarty, J., Ottlé, C., Braud, I., Olioso, A., Frangi, J.P., Bastidas, L.A., Gupta, H.V., 2004. 1210 Using a multiobjective approach to retrieve information on surface properties used in a 1211 SVAT model. J. Hydrol. 287, 214-236.

1212 Demarty, J., Ottlé, C., Braud, I., Olioso, A., Frangi, J.P., Gupta, H.V., Bastidas, L.A., 2005. 1213 Constraining a physically based Soil-Vegetation-Atmosphere Transfer model with surface water content and thermal infrared brightness temperature measurements using a

1219 Fisher, J.I., Mustard, J.F., Vadeboncoeur M.A., 2006. Green leaf phenology at Landsat 1220 resolution: scaling from the field to the satellite. Remote Sens. Environ. 100, 265-279.

1221 Galleguillos, M., Jacob, F., Prévot, L., French, A., Lagacherie, P., 2011. Comparison of two 
temperature differencing methods to estimate daily evapotranspiration over a Mediterranean vineyard watershed from ASTER data. Remote Sens. Environ. 115, 13261340.

1225 Gaudin, R., Celette, F., Gary, C., 2010. Contribution of runoff to incomplete off season soil 1226 water refilling in a Mediterranean vineyard. Agr. Water Manage. 97, 1534-1540.

1227 Gharari, S., Hrachowitz, M., Fenicia, F., Savenije, H.H.G., 2013. An approach to identify 1228 time consistent model parameters: sub-period calibration. Hydrol. Earth Syst. Sci. 17, 149-161.

1230 Graser, E.A., Van Babel, C.H.M., 1982. The effect of soil moisture upon soil albedo. Agr. 1231 Meteorol. 27, 17-26.

1232 Guillevic, P.C., Privette, J.L., Coudert, B., Palecki, M.A., Demarty, J., Ottlé, C., Augustine, 1233 J.A., 2012. Land Surface Temperature product validation using NOAA's surface climate 1234 observation networks - scaling methodology for the Visible Infrared Imager Radiometer Suite (VIIRS). Remote Sens. Environ. 124, 282-298.

Guix-Hébrard, N., Voltz, A., Trambouze, W., Garnier, F., Gaudillère, J.P., Lagacherie, P., 2007. Influence of watertable depths on the variation of grapevine water status at the landscape scale. Eur. J. Agron. 27, 187-196.

Gupta, H.V., Bastidas, L.A., Sorooshian, S., Shuttleworth, W.J., Yang, Z.L., 1999. Parameter estimation of a land surface scheme using multicriteria methods. J. Geophys. Res. 104, 19491-19503.

Hicks, B.B., 1973. Eddy flux over a vineyard. Agric. For. Meteorol. 12, 203-215.

Holland, S., Heitman, J.L., Howard, A., Sauer, T.J., Giese, W., Ben-Gal, A., Agam, N., Kool, D., Havlin, J., 2013. Micro-Bowen ratio system for measuring evapotranspiration in a vineyard interrow. Agric. Forest Meteorol. 177, 93-100.

Idso, S.B., Jackson, R.D., 1969. Thermal radiation from the atmosphere. J. Geophys. Res. 74,

1248 Idso, S.B., Jackson, R.D., Reginato, R.J., Kimball, B.A., Nakayama, F.S., 1975. The dependence of bare soil albedo on soil water content. J. Appl. Meteorol. 14, 109-113.

Jarvis, P.G., 1976. The interpretation of leaf water potential and stomatal conductance found in canopies in the field. Phil. Trans. Roy. Soc. Lond. B. 273, 593-610.

1253 heating rates as proxy surface wetness data into a regional atmospheric mesoscale model. 1254 Part I: Methodology. Mon. Wea. Rev. 126, 634-645.

1255 Jones, H.G., Stoll, M., Santos, T., de Sousa, C., Chaves, M.M., Grant, O.M., 2002. Use of 
infrared thermography for monitoring stomatal closure in the field: application to grapevine. J. Exp. Bot. 53 (378), 2249-2260.

1258 Kustas, W.P., Zhan, X., Schmugge, T.J., 1998. Combining optical and microwave remote 1259 sensing for mapping energy fluxes in a semiarid watershed. Remote Sens. Environ. 64, $1260 \quad 116-131$.

1261 Lebon, E., Dumas, V., Pieri, P., Schultz, H.R., 2003. Modelling the seasonal dynamics of the 1262 soil water balance of vineyards. Funct. Plant Biol. 30, 699-710.

1263 Lhomme, J.P., Chehbouni, A., 1999. Comments on dual-source vegetation-atmosphere 1264 transfer models. Agr. Forest Meteorol. 94, 269-273.

Lhomme, J.P., Monteny, B., 2000. Theoretical relationship between stomatal resistance and surface temperatures in sparse vegetation. Agr. Forest Meteorol. 104, 119-131.

Lhomme, J.P., Vacher, J.J., Rocheteau, A., 2007. Estimating downward long-wave radiation on the Andean Altiplano. Agr. Forest Meteorol. 145, 139-148.

Lhomme, J.P., Montes, C., Jacob, F., Prévot, L., 2012. Evaporation from heterogeneous and sparse canopies: on the formulations related to multi-source representations. Bound.-Lay. Meteorol. 144, 243-262.

Mahfouf, J.-F., and J. Noilhan, 1991. Comparative study of various formulations of evaporation from bare soil using in-situ data. J. Appl. Meteorol., 30, 1354-1365.

Maxwell, R.M., Miller, N.L., 2005. Development of a coupled land surface and groundwater model. J. Hydrometeorol. 6, 233-247.

Monteith, J.L., 1965. Evaporation and the environment, in: The state and movement of water in living organisms, XIX symposium, Soc. Exp. Biol., Swansea, Cambridge University Press, 205:234.

Morlat, R., Jacquet A., 2003. Grapevine root system and soil characteristics in a vineyard maintained long-term with or without interrow sward. Am. J. Enol. Vitic. 54, 1-7.

Moussa, R., Chahinian, N., Bocquillon, C., 2007. Distributed hydrological modelling of a Mediterranean mountainous catchment - Model construction and multi-site validation. J. Hydrol. 337, 35-51.

Norman, J.M., Kustas, W.P., Humes, K.S., 1995. Source approach for estimating soil and vegetation energy fluxes in observations of directional radiometric surface temperature.

1287 Ortega-Farias, S., Carrasco, M., Olioso, A., Acevedo, C., Poblete, C., 2007. Latent heat flux 1288 over Cabernet Sauvignon vineyard using the Shuttleworth and Wallace model. Irrigation 1289 Sci. 25, 161-170. 
1290 Ortega-Farias, S., Poblete-Echeverría, C., Brisson, N., 2010. Parameterization of a two-layer 1291 model for estimating vineyard evapotranspiration using meteorological measurements. 1292 Agr. Forest Meteorol. 150, 276-286.

1293 Padro, J., Massman, W.J., Den Hartog, G., Neumann, H.H., 1994. Dry deposition velocity of $1294 \mathrm{O}_{3}$ over a vineyard obtained from models and observations: The 1991 California ozone 1295 deposition experiment. Water Air Soil Pollut. 75, 307-323.

1296 Paré, N., 2011. Construction d'un modèle couplé pression-impact pour l'expérimentation virtuelle de pratiques culturales à l'échelle de petits bassins versants. PhD Thesis,

1299 Pellegrino, A., Lebon, E., Simonneau, T.M., Wery, J., 2005. Towards a simple indicator of 1300 water stress in grapevine (Vitis vinifera L.) based on the differential sensitivities of 1301 vegetative growth components. Aust. J. Grape Wine Res. 11, 306-315.

1302 Pieri, P., 2010a. Modelling radiative balance in a row-crop canopy: Cross-row distribution of 1303 net radiation at the soil surface and energy available to clusters in a vineyard. Ecol. Model. 221, 802-811.

1305 Pieri, P., 2010b. Modelling radiative balance in a row-crop canopy: Row-soil surface net radiation partition. Ecol. Model. 221, 791-801.

1307 Pieri, P., Gaudillère, J.P., 2003. Sensitivity to training system parameters and soil surface 1308 albedo of radiation intercepted by vine rows. Vitis. 42, 77-82.

1309 Poblete-Echeverria, C., Ortega-Farias, S., 2009. Estimation of actual evapotranspiration for a 1310 drip-irrigated Merlot vineyard using a three-source model. Irrigation Sci. 28, 65-78.

1311 Pradel, C., Pieri, P., 2000. Influence of a grass layer on vineyard soil temperature. Aust. J. 1312 Grape Wine Res. 6, 59-67.

1313 Raes, D., Deproost, P., 2003. Model to assess water movement from a shallow water table to 1314 the root zone. Agr. Water Manage. 62, 79-91.

1315 Rana, G., Katerji, N., 2008. Direct and indirect methods to simulate the actual 1316 evapotranspiration of an irrigated overhead table grape vineyard under Mediterranean 1317 conditions. Hydrol. Process. 22, 181-188.

1318 Raupach, M.R., 1989. A practical Lagrangian method for relating scalar concentrations to 1319 source distributions in vegetation canopies. Q. J. Roy. Meteorol. Soc. 115, 609-632.

1320 Riou, C., Pieri, P., Valancogne, C., 1987. Variation de la vitesse du vent a l'intérieur et au1321 dessus d'une vigne. Agr. Forest Meteorol. 39, 143-154.

1322 Riou, C., Valancogne, C., Pieri, P., 1989. Un modèle simple d'interception du rayonnement 1323 solaire par la vigne - Vérification expérimentale. Agronomie. 9, 441-450. 
1324 Riou, C., Pieri, P., Le Clech, B., 1994. Consommation d'eau de la vigne en conditions 1325 hydriques non limitantes. Formulation simplifies de la transpiration. Vitis. 33, 109-115.

1326 Rodriguez-Iturbe, I., 2000. Ecohydrology: A hydrologic perspective of climate-soil1327 vegetation dynamics. Water Resour. Res. 36, 3-9.

1328 Saux-Picart, S., Ottlé, C., Perrier, A., Decharme, B., Coudert, B., Zribi, M., Boulain, N., 1329 Cappelaere, B., Ramier, D., 2009. SEtHyS_Savannah: A multiple source land surface 1330 model applied to Sahelian landscapes. Agr. Forest Meteorol. 149, 1421-1432.

1331 Schultz, H.R., 1996. Water relations and photosynthetic response of two grapevine cultivars 1332 of different geographical origin during water stress. Acta Hortic. 427, 251-266.

1333 Sene, K.J., 1994. Parameterisations for energy transfers from a sparse vine crop. Agr. Forest 1334 Meteorol. 71, 1-18.

1335 Sene, K.J., 1996. Meteorological estimates for the water balance of a sparse vine crop 1336 growing in semiarid conditions. J. Hydrol. 179, 259-280.

1337 Sellers, P.J., Heiser, M.D., Hall, F.G., 1992. Relations between surface conductance and 1338 spectral vegetation indices at intermediate $\left(100 \mathrm{~m}^{2}\right.$ to $\left.15 \mathrm{~km}^{2}\right)$ length scales. J. Geophys. Res. 97, 19033-19059.

Shuttleworth, W.J., Wallace, J.S., 1985. Evaporation from sparse crops - an energy combination theory. Q. J. Roy. Meteor. Soc. 111, 839-855.

Shuttleworth, W.J., Gurney, R.J., 1990. The theoretical relationship between foliage temperature and canopy resistance in sparse crops. Q. J. Roy. Meteor. Soc. 111, 839-855.

Sini, F., Boni, G., Caparrini, F., Entekhabi, D., 2008. Estimation of large-scale evaporation fields based on assimilation of remotely sensed land temperature . Water. Resour. Res. 44, W06410, doi:10.1029/2006WR005574 .

Siqueira, M., Katul, G., Porporato, A., 2008. Onset of water stress, hysteresis in plant conductance, and hydraulic lift: Scaling soil water dynamics from millimeters to meters. 44, W01432, doi:10.1029/2007WR006094.

Soylu, M.E., Istanbulluoglu, E., Lenters, J.D., Wang, T., 2011. Quantifying the impact of groundwater depth on evapotranspiration in a semi-arid grassland region. Hydrol. Earth Syst. Sci. 15, 787-806.

1353 Spano, D., Snyder, R.L., Sirca, C., Duce, P., 2009. ECOWAT - A model for ecosystem 1354 evapotranspiration estimation. Agr. Forest Meteorol. 149, 1584-1596.

1355 Stewart, J.B., 1988. Modelling surface conductance of pine forest. Agr. Forest. Meteorol. 43, $1356 \quad 19-35$.

1357 Taconet, O., Bernard, R., Vidal-Madjar, D., 1986. Evapotranspiration over an agricultural 
region using a surface flux/temperature model based on NOAA-AVHRR data. J. Clim. Appl. Meteorol. 25, 284-307.

1360 Trambouze, W., Bertuzzi, P., Voltz, M., 1998. Comparison of methods for estimating actual 1361 evapotranspiration in a row-cropped vineyard. Agr. Forest Meteorol. 91, 193-208.

1362 Trambouze, W., Voltz, M., 2001. Measurement and modelling of the transpiration of a 1363 Meditarranean vineyard. Agr. Forest Meteorol. 107, 153-166.

1364 Tuzet, A., Perrier, A., Leuning, R., 2003. A coupled model of stomatal conductance, photosynthesis and transpiration. Plant Cell Environ. 26, 1097-1116.

Van den Hurk, B.J.J.M., McNaughton, K.G., 1995. Implementation of near-field dispersion in a simple two-layer surface resistance model. J. Hydrol. 166, 293-311.

1368 Vaudour, E., 2003. Les terroirs viticoles. Dunod, Paris, 312p.

1369 Verhoef, A., Allen, S.J., 2000. A SVAT scheme describing energy and $\mathrm{CO}_{2}$ fluxes for multicomponent vegetation: calibration and test for a Sahelian savannah. Ecol. Model. 127, 245-267.

Volpe, V., Marani, M., Albertson, J.D., Katul, G., 2013. Root controls on water redistribution and carbon uptake in the soil-plant system under current and future climate. Adv. Water Resour. 60, 110-120.

Weiss, A., Allen, L.H.J., 1976. Air flow patterns in vineyard rows. Agric. Meteorol. 16, 329342.

Winkel, T., Rambal, S., 1990. Stomatal conductance of some grapevines growing in the field under Mediterranean environment. Agr. Forest Meteorol. 51, 107-121.

Winkler, A.J., Williams, W.O., 1939. The hear required to bring Tokay grapes to maturity. Proceedings of the American Society of Horticultural Science. 37, 650-652.

Wu, A., Black, A., Verseghy, D.L., Bailey, W.G., 2001. Comparison of two-layer and singlelayer canopy models with Lagrangian and $K$-theory approaches in modeling evaporation from forests. Int. J. Climatol. 21, 1821-1839.

Yi, C. 2008. Momentum transfer within canopies, J. Appl. Meteorol. Climatol. 47, 262-275. models to Bowen ratio-energy balance method for a vineyard in a desert region of northwest China. Agr. Forest Meteorol. 148, 1629-1640.

Zhang, Y.-K., Schilling, K.E., 2006. Effects of land cover on water table, soil moisture 
1392 evapotranspiration, and groundwater recharge: A field observation and analysis. J. $1393 \quad$ Hydrol. 319, 328-338.

1394 Zhang, B., Kang, S., Zhang, L., Tong, L., Du, T., 2009. An evapotranspiration model for 1395 sparsely vegetated canopies under partial root-zone irrigation. Agr. Forest Meteorol. 149, 1396 2007-2011. 
1397 Table 1. Uncertainty range and final values for the fitted parameters of the plant-atmosphere model, as obtained from the MCIP calibration.

\begin{tabular}{|c|c|c|c|c|}
\hline Parameter & Equation & Description (units) & Initial uncertainty range & $\begin{array}{c}\text { Final } \\
\text { calibrated } \\
\text { value }\end{array}$ \\
\hline \multicolumn{5}{|c|}{ Biophysical parameters } \\
\hline$c$ & 7 and 15 & Extinction coefficient of main foliage (-) & $0.3-0.7$ & 0.45 \\
\hline$\beta_{v s}$ & 9 & Soil heat flux fraction for vegetated soil (-) & $0.1-0.4$ & 0.28 \\
\hline$\beta_{b s}$ & 10 & Soil heat flux fraction for bare soil (-) & $0.2-0.5$ & 0.38 \\
\hline$g_{x, f}$ & 17 & Maximal stomatal conductance (main foliage) $\left(\mathrm{m} \mathrm{s}^{-1}\right)$ & $1.25 \times 10^{-3}-1.2 \times 10^{-2}$ & $3.3 \times 10^{-3}$ \\
\hline$g_{x, v s}$ & 17 & Maximal stomatal conductance (vegetated soil) $\left(\mathrm{m} \mathrm{s}^{-1}\right)$ & $3.3 \times 10^{-3}-1.0 \times 10^{-2}$ & $3.7 \times 10^{-3}$ \\
\hline$a_{f}$ & 16 & Foliage albedo (-) & $0.1-0.4$ & 0.24 \\
\hline$a_{b s}$ & 16 & Bare soil albedo (-) & $0.2-0.5$ & 0.3 \\
\hline$a_{v s}$ & 16 & Grass albedo (-) & $0.15-0.35$ & 0.25 \\
\hline \multicolumn{5}{|c|}{ Empirical parameters } \\
\hline$K_{1}^{f}$ & 18 & Parameter of PAR stress function (main foliage) $\left(\mu \mathrm{mol} \mathrm{m}^{-2} \mathrm{~s}^{-1}\right)$ & $80-200$ & 150 \\
\hline$K_{1}^{v s}$ & 18 & Parameter of PAR stress function (vegetated soil) $\left(\mathrm{W} \mathrm{m}^{-2}\right)$ & $80-140$ & 112 \\
\hline$K_{2}^{f}$ & 19 & Parameter of $D_{a}$ stress function (main foliage) $\left(\mathrm{kPa}^{-1}\right)$ & $1.575 \times 10^{-4}-3.125 \times 10^{-4}$ & $2.0 \times 10^{-4}$ \\
\hline$K_{2}^{v s}$ & 19 & Parameter of $D_{a}$ stress function (vegetated soil) $\left(\mathrm{kPa}^{-1}\right)$ & $3.5 \times 10^{-2}-1.05 \times 10^{-1}$ & $7.0 \times 10^{-2}$ \\
\hline$K_{3}^{f}$ & 20 & Parameter of $\theta$ stress function (main foliage) (-) & $10-100$ & 35 \\
\hline$K_{3}^{v s}$ & 20 & Parameter of $\theta$ stress function (vegetated soil) (-) & $10-100$ & 45 \\
\hline$A_{1}$ & 21 & Parameter of bare soil resistance (-) & $5-15$ & 8 \\
\hline$B_{1}$ & 21 & Parameter of bare soil resistance (-) & $1-10$ & 5 \\
\hline
\end{tabular}


1400 Table 2. Measured and estimated values of parameters used in the soil water balance model. 1401

\begin{tabular}{|c|c|c|c|}
\hline Soil parameter & Value & Units & Informative source \\
\hline \multicolumn{4}{|c|}{ Soil profile description } \\
\hline$\theta_{n, 1}$ & 0.05 & $\mathrm{~m}^{3} \mathrm{~m}^{-3}$ & Trambouze and Voltz, 2001 \\
\hline$\theta_{n, 2}=\theta_{n, 3}=\theta_{f, w p}$ & 0.15 & $\mathrm{~m}^{3} \mathrm{~m}^{-3}$ & Trambouze and Voltz, 2001 \\
\hline$\theta_{f c, 1}$ & 0.246 & $\mathrm{~m}^{3} \mathrm{~m}^{-3}$ & Measured \\
\hline$\theta_{f c, 2}$ & 0.268 & $\mathrm{~m}^{3} \mathrm{~m}^{-3}$ & Measured \\
\hline$\theta_{f c, 3}$ & 0.331 & $\mathrm{~m}^{3} \mathrm{~m}^{-3}$ & Measured \\
\hline$p_{1}$ & 0.16 & Fraction & Measured \\
\hline$p_{2}$ & 0.20 & Fraction & Measured \\
\hline$p_{3}$ & 0.16 & Fraction & Measured \\
\hline \multicolumn{4}{|c|}{ Capillary rise equations } \\
\hline$\Psi_{s, 3}$ & 0.63 & $\mathrm{~m}$ & Clapp and Hornberger (1978) \\
\hline$\Psi_{G}$ & 0.63 & $\mathrm{~m}$ & Clapp and Hornberger (1978) \\
\hline$\theta_{s, 3}$ & 0.476 & $\mathrm{~m}^{3} \mathrm{~m}^{-3}$ & Clapp and Hornberger (1978) \\
\hline$K_{s, 3}$ & $2.45 \times 10^{-6}$ & $\mathrm{~m} \mathrm{~s}^{-1}$ & Clapp and Hornberger (1978) \\
\hline$b_{3}$ & 8.52 & - & Clapp and Hornberger (1978) \\
\hline \multicolumn{4}{|l|}{ Reservoirs depth } \\
\hline$z_{1}$ & 0.05 & $\mathrm{~m}$ & Locally estimated \\
\hline$z_{2}$ & 0.50 & $\mathrm{~m}$ & Locally estimated \\
\hline$z_{R}$ & 2.0 & $\mathrm{~m}$ & Locally estimated \\
\hline
\end{tabular}

1402 
1405 Fig. 1. Schematic representation of the three-source evaporation model and the soil water 1406 transfer model. $r_{a, f}$ is the bulk boundary-layer resistance of the main foliage for water vapor 1407 transfer $\left(r_{a, f}=2 r_{a, f, h}\right)$. See list of symbols for other parameters definition. Numbers (1), (2) and 1408 (3) denote the three soil reservoirs related to evaporation components $f$ (main foliage), vs 1409 (vegetated soil) and $b s$ (bare soil).

1410

1411

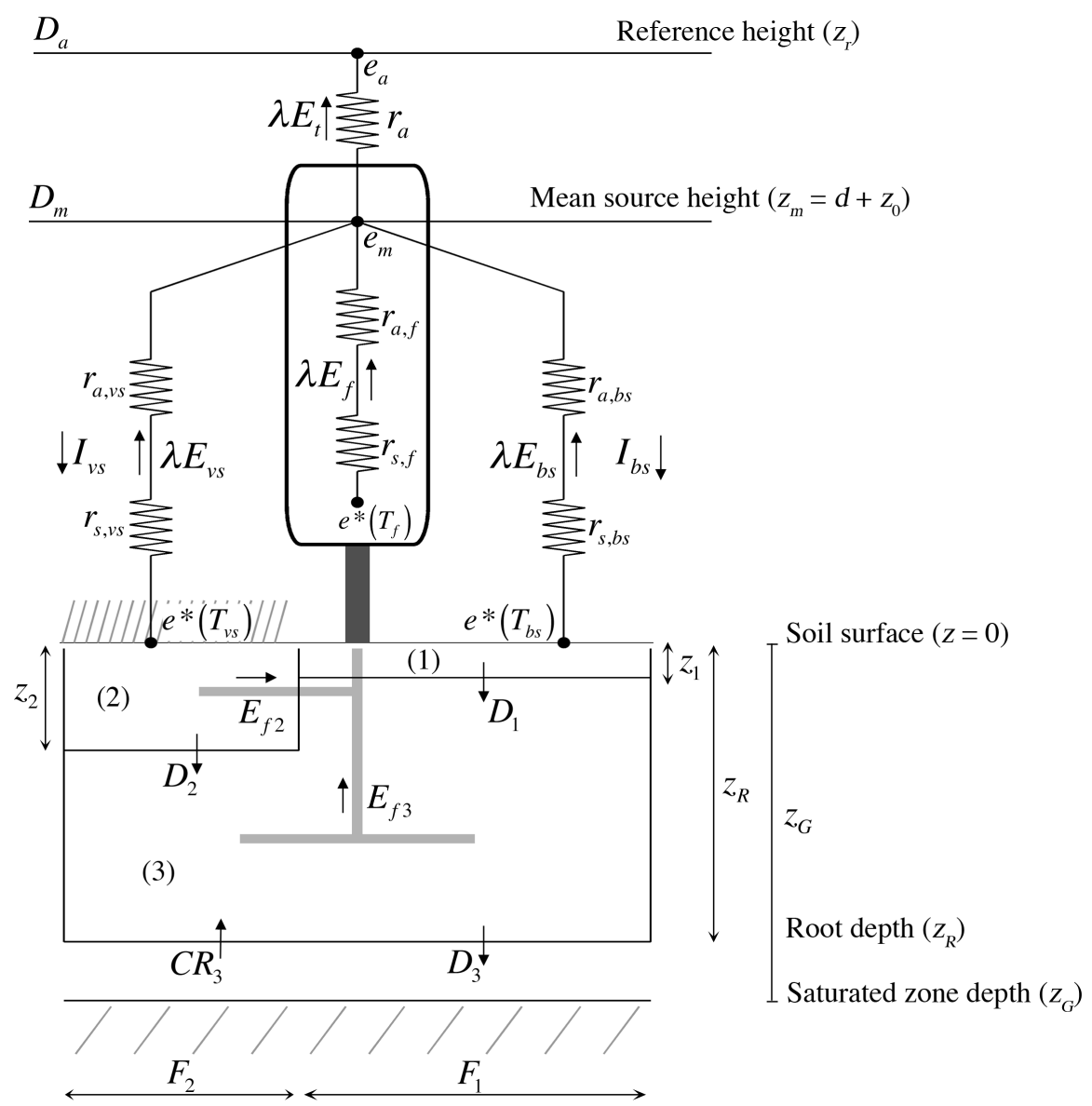

1413

1414 
1416 Fig. 2. Time series of meteorological variables, as measured during the simulation period, and

1417 used for model forcing. Gray shaded bars show periods of evaporation measurements used for

1418 model validation. (a)-(b) Daily incident solar radiation; (c)-(d) daily mean air temperature;

1419 (e)-(f) daily mean relative humidity; (g)-(h) daily mean wind speed; (i)-(j) daily accumulated 1420 precipitation. Also, simulated $L A I_{f}$ (Eq. (37)) and estimated CLAI $I_{v s}$ are shown in (k)-(1). 1421 Circles in (1) are $L A I_{f}$ measurements. Shaded intervals in (c) to (h) represent daily minimum 1422 and maximum values. Abscise labels denote the beginning of each month.
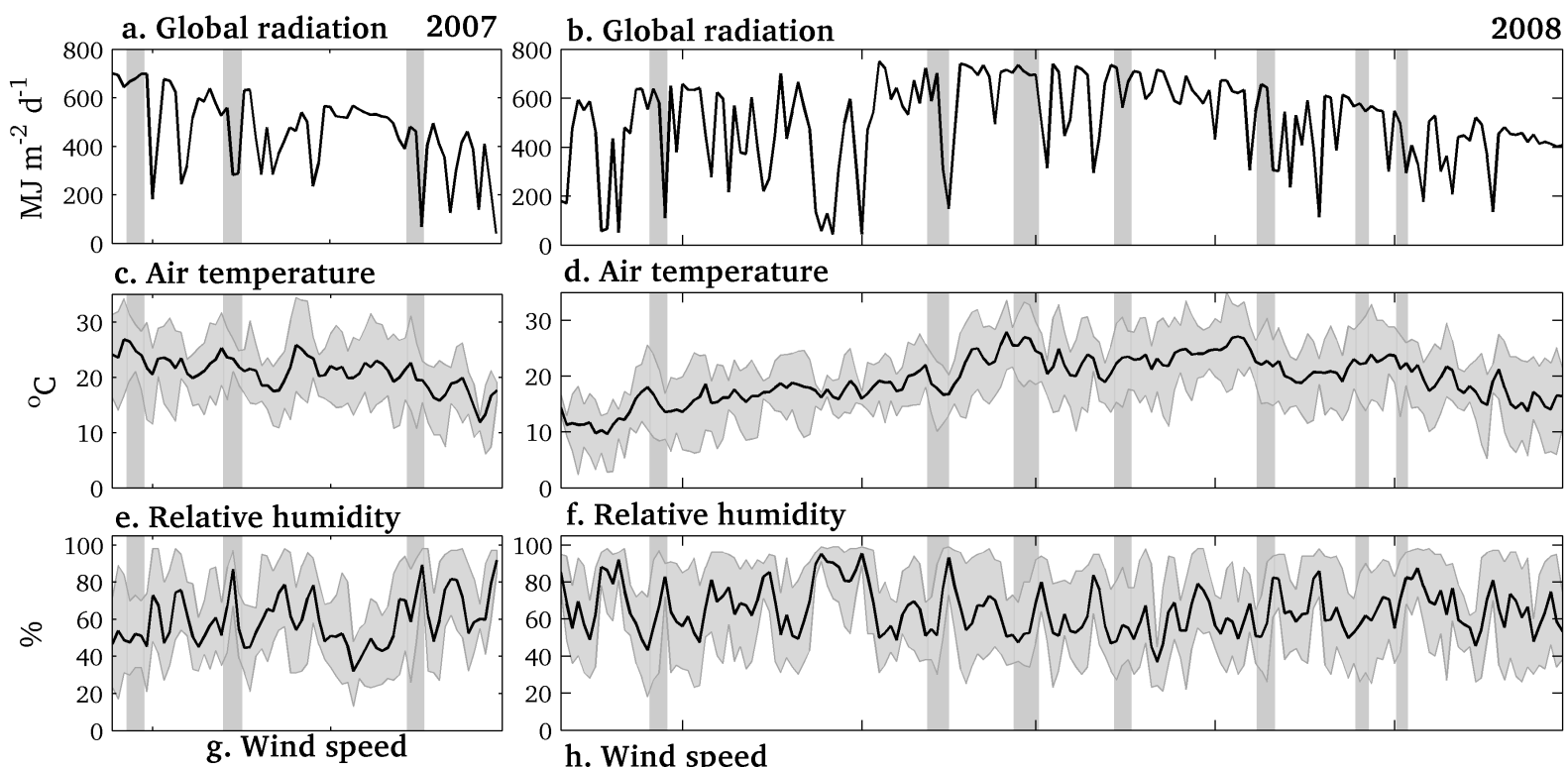

f. Relative humidity
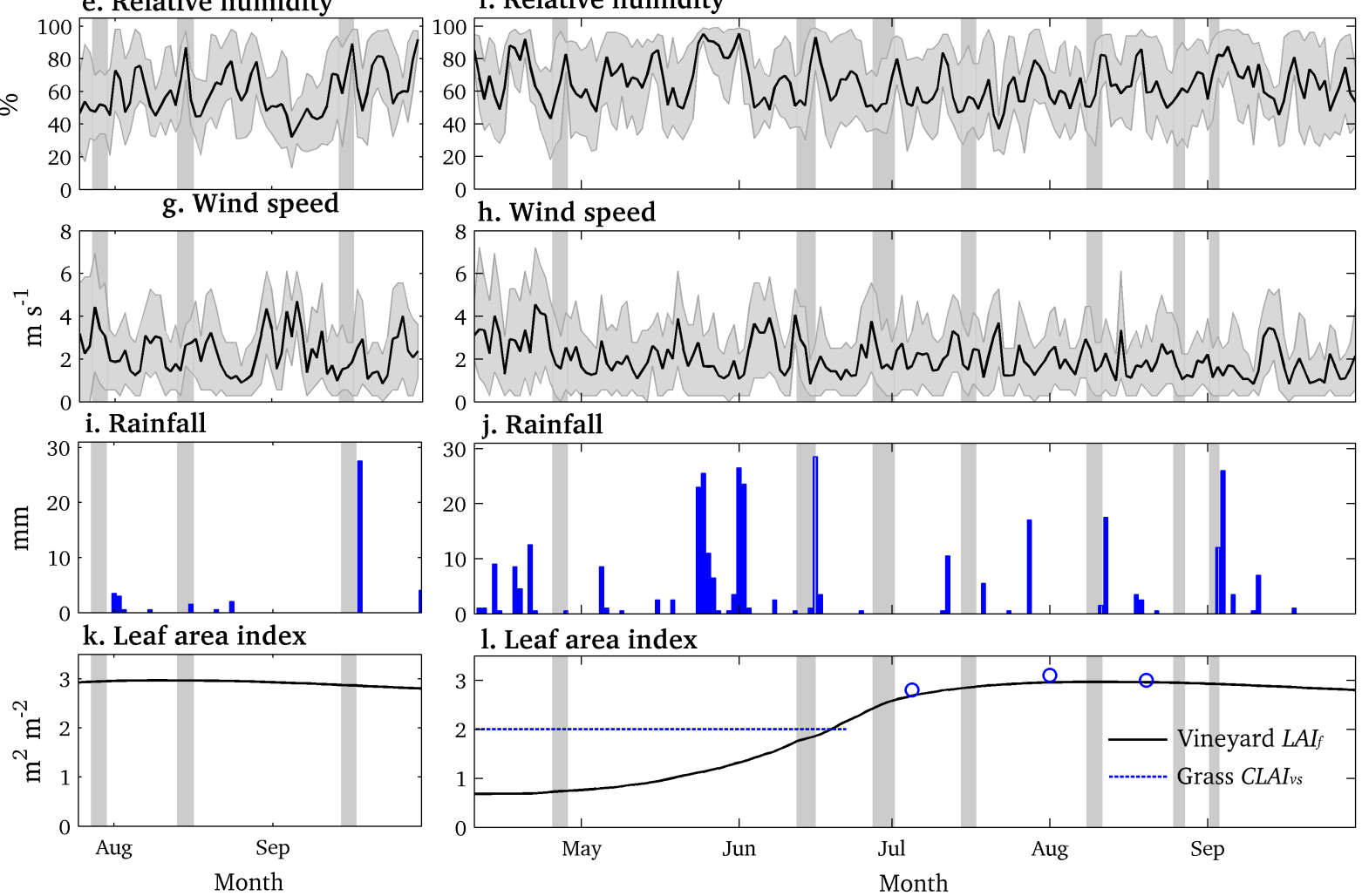
1426 Fig. 3. Scatter plot of hourly measured and simulated total latent heat flux $\left(\lambda E_{t}\right)$.

1427

1428

1429

1430

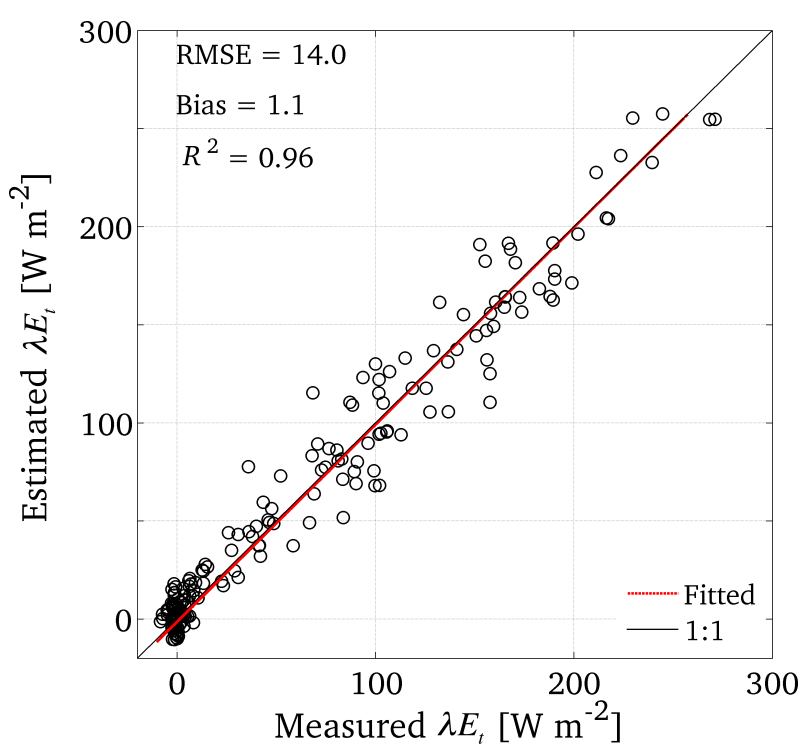

1431

1432

1433

1434 
1436 Fig. 4. Time series of simulated (lines) and measured (circles) hourly latent heat flux ( $\left.\lambda E_{t}\right)$ for 1437 eight observation days.

\section{8}

1439

(a) 29-Jul-2007
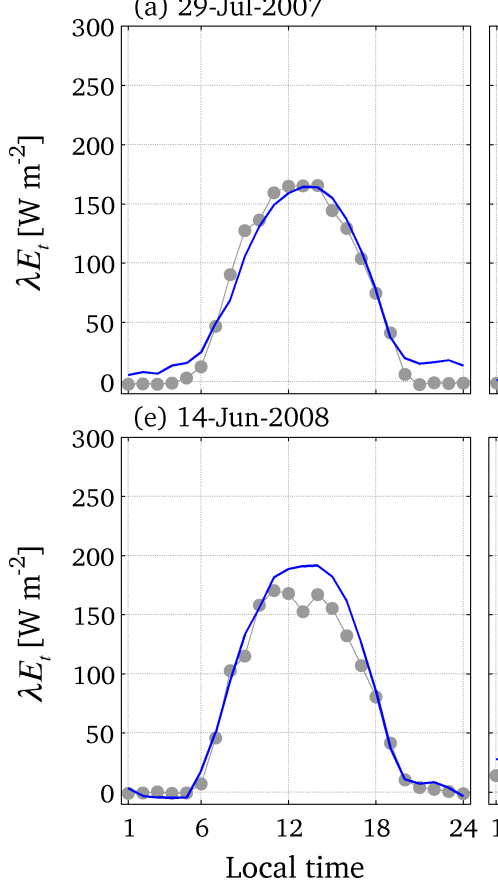

(b) 14-Aug-2007

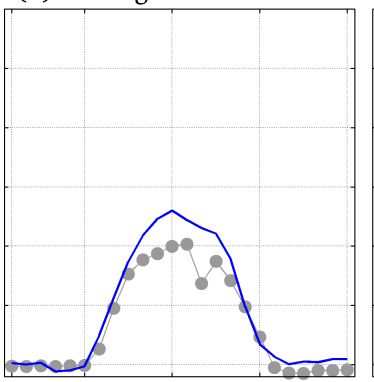

(f) 30-Jun-2008

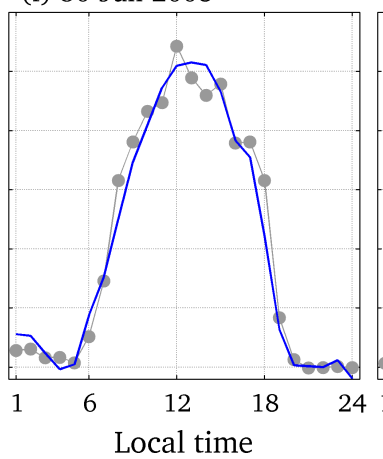

(c) $15-$ Sep-2007

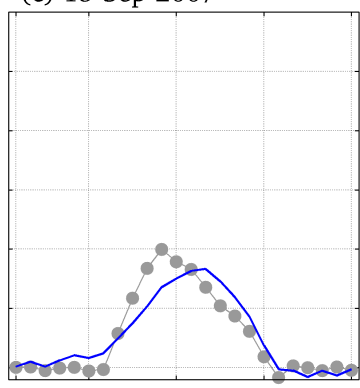

(g) 16-Jul-2008

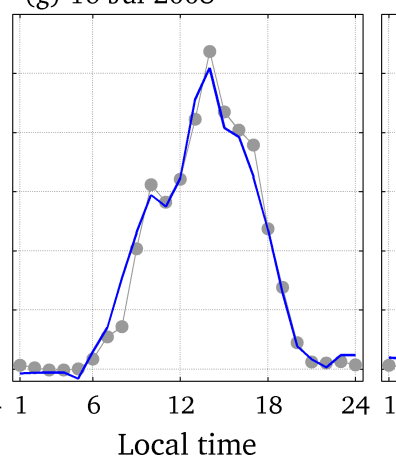

(d) 26-Apr-2008

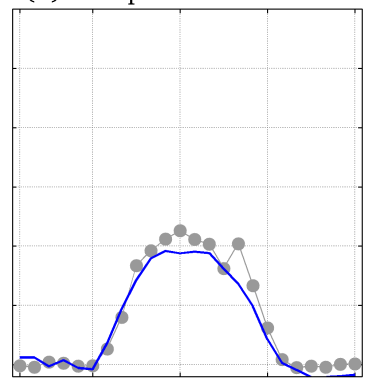

(h) 09-Aug-2008

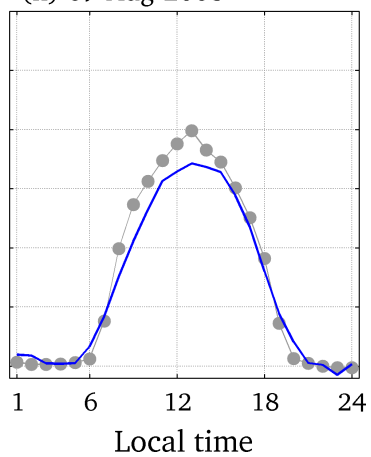

1441 
1443 Fig. 5. Scatter plot of daily (a) total evaporation $\left(E_{t}\right)$ and (b) soil water content $(\theta)$ as 1444 measured and as simulated by the model. In (a) only days with 24 hours of measurements 1445 were included.

1446

1447
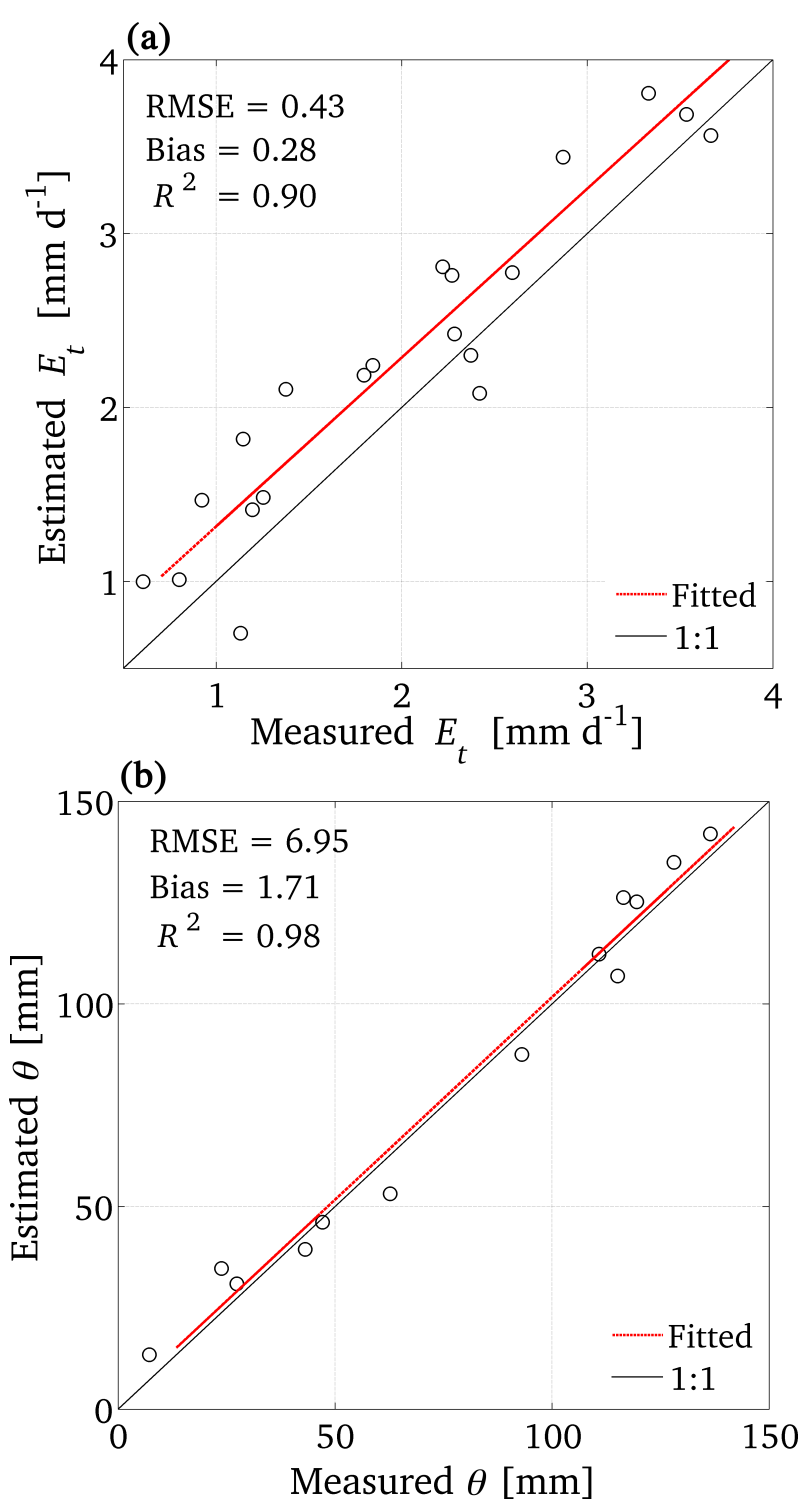

1449 
1455 Fig. 6. Time series of (a) simulated (line) and observed (circles) daily total evaporation, and 1456 (b) simulated (line) and observed (circles) integrated profile volumetric soil water content. 1457 Abscissa labels denote the beginning of each month.

1458

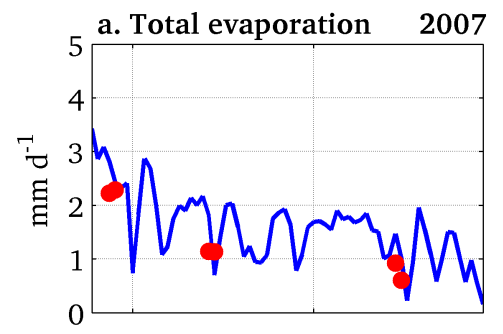

c. Soil water content

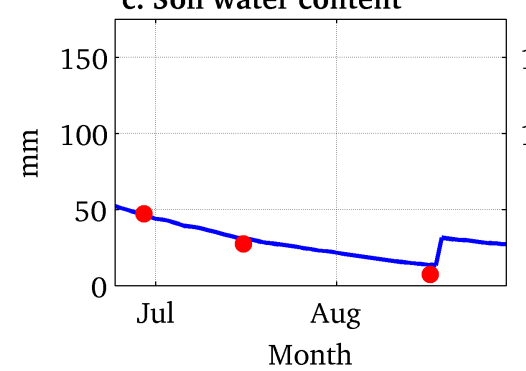

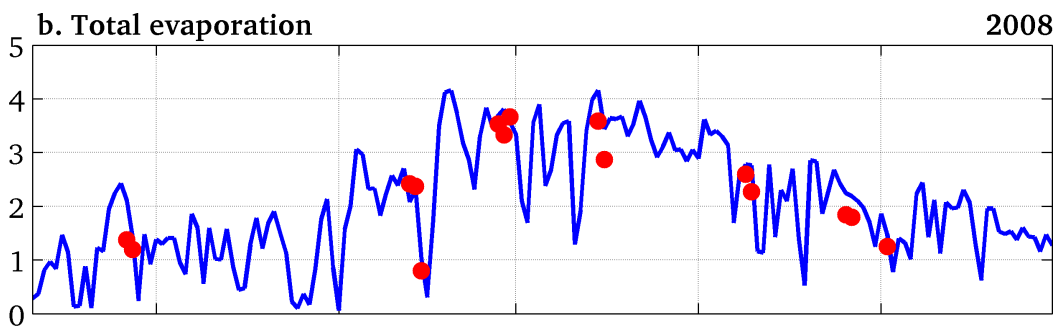

d. Soil water content

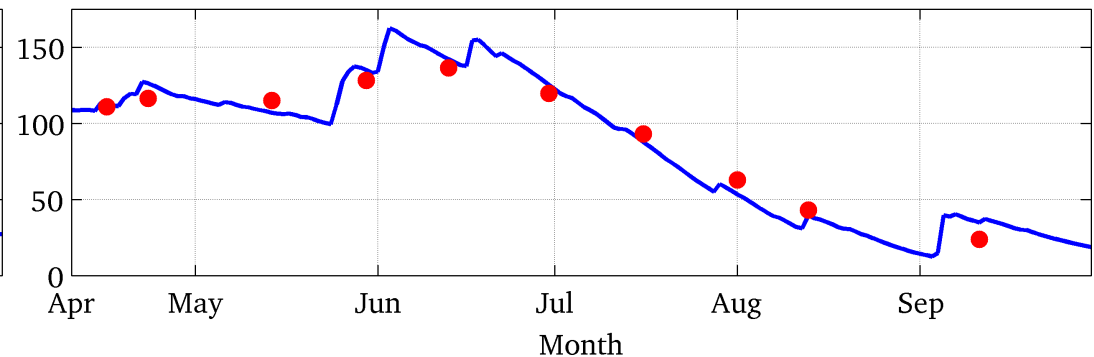

1460

1461

1462

1463 
1465 Fig. 7. Capillary flow (contours in $\mathrm{mm} \mathrm{d}^{-1}$ ) between saturated zone and reservoir (3) as a 1466 function of the distance between water table $\left(z_{G}\right)$ and root zone depth $\left(z_{R}\right)$ and soil water 1467 content of reservoir (3). Upward flow is taken as positive values.

1468

1469

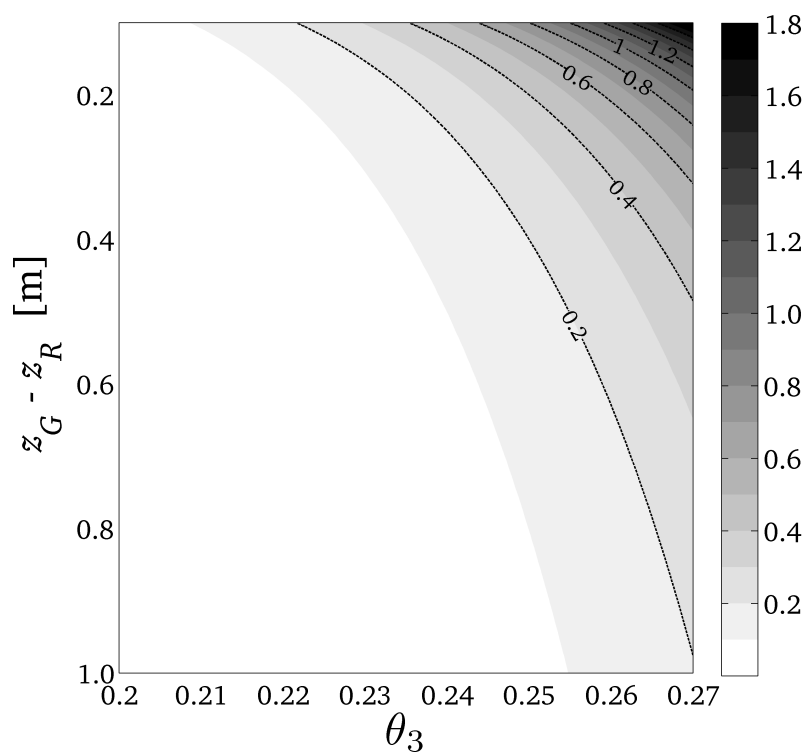

1471

1472

1473

1474 
1476 Fig. 8. Simulated total evaporation (contours in $\mathrm{mm} \mathrm{h}^{-1}$ ) as a function of the spacing between 1477 vine rows $w_{i}$ and the grass cover fraction $F_{v s}$.

1478

1479

1480

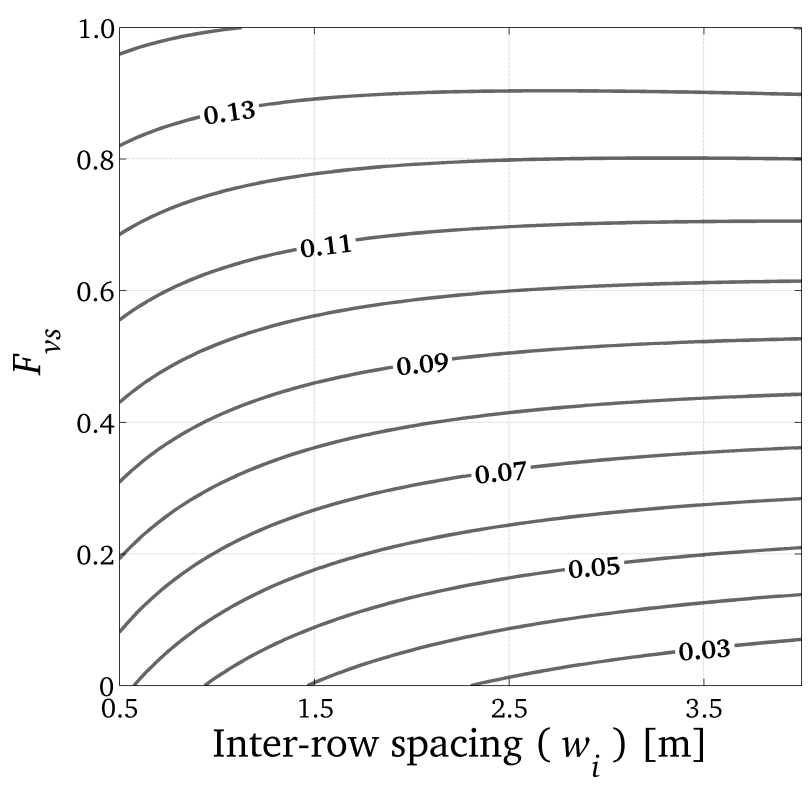

1481 